\title{
A decision-support methodology for assessing the sustainability of natural risk management strategies in urban areas
}

\author{
A. M. Edjossan-Sossou ${ }^{1,2}$, O. Deck ${ }^{1}$, M. Al Heib ${ }^{2}$, and T. Verdel ${ }^{1}$ \\ ${ }^{1}$ Université de Lorraine, GeoRessources, UMR 7359, Ecole des Mines de Nancy, Campus Artem, CS 14234, \\ Nancy CEDEX, 54042, France \\ ${ }^{2}$ INERIS Nancy, c/o Ecole des Mines de Nancy, Campus Artem, CS 14234, Nancy CEDEX, 54042, France \\ Correspondence to: A. M. Edjossan-Sossou (abla-mimi.edjossan-sossou@ univ-lorraine.fr)
}

Received: 5 December 2013 - Published in Nat. Hazards Earth Syst. Sci. Discuss.: 14 January 2014

Revised: 15 October 2014 - Accepted: 3 November 2014 - Published: 4 December 2014

\begin{abstract}
This paper attempts to provide a decision support framework that can help risk managers in urban areas to improve their decision-making processes related to sustainable management. Currently, risk management strategies should no longer be selected based primarily on economic and technical insight. Managers must address the sustainability of risk management by assessing the impacts of their decisions on the sustainable development of a given territory. These assessments require tools that allow ex ante comparisons of the effectiveness and the likely economic, social and ecological impacts of the alternative management strategies. Therefore, this paper reports a methodological and operational framework, which aims to incorporate sustainability principles in a particular decision by taking all the dimensions that affect sustainability into account. This paper is divided into two main parts: one on the theoretical aspects of the proposed methodology and the other on its application to a flood risks management case in a municipality located in Meurthe-etMoselle county (France). The results of the case study have shown how the methodology can be suitable for determining the most sustainable decision.
\end{abstract}

\section{Introduction and background}

In this paper, we propose a framework to examine the sustainability of risk management measures. The capacity for risk response toward natural hazards exists within societies to different degrees. Various mechanisms like "land-use planning", "financial compensation and insurance", "awareness raising", "strengthening of early warning systems", and "structural enhancement of buildings" are some of strategies deployed to manage prevalent natural risks. However, not all responses are sustainable (Tompkins and Adger, 2004). Planners continue unsustainable practices because they do not sufficiently factor sustainability principles into their management decisions. Consequently, those decisions engender conflicts between economic and social/environmental interests or prove unacceptable under societal/ecological standards. A consistent use of this framework would improve the adequacy assessments used under different management strategies or combinations of strategies, using sustainability principles.

Urban areas are complex systems through their people concentration, growing population, role as economic activities drivers, architectural structures, water and electric power supply systems, and communications networks. Unfortunately, many of these features that define and make cities attractive also constitute their critical problems. These features contribute to render cities increasingly vulnerable to threats from various kinds of risks (McBean and Henstra, 2003). Cities experienced risks from terrorist attacks, criminal activities, industrial accidents, transportation troubles, infrastructure failures, public health emergencies, and natural hazards (e.g. earthquakes, floods, grassland fires, landslides, tornadoes).

In recent years, cities have become extremely vulnerable to the latter events (Hansson et al., 2008). They have faced many catastrophic events due to natural hazards, which resulted in significant levels of casualties and economic damages. Those events also caused tremendous disruptions to cities socio-economic activities, and/or to their environment. 
As such, these disasters have highlighted the vulnerability of urban areas to natural risks all over the world. There is a growth of risks due to natural hazards, and accordingly, the losses created by those hazards have become increasingly serious. Throughout the past years, natural disasters such as floods in Vaison-la-Romaine (France, 1992), European heat wave (2003), hurricane Katrina in United States (2005), earthquake in Haiti (2010), windstorm Xynthia and sea surge in La Faute-sur-Mer (France, 2010), earthquake and tsunami in Japan (2011), and central European flood (2013) remind us the increasing losses, which urban areas are facing from natural hazards. It is evidence that these losses can compromise socio-economic development for years (Faber, 2010; Ni et al., 2010). Consequently, the management of risks due to natural hazards can be considered "a specific element of sustainable development" (Peltonen, 2006; Knott and Fox, 2010).

Therefore, one of the key challenges for cities is to reduce their economic, social and ecological vulnerability to natural hazards and to manage their response to those hazards (in order to reduce hazard occurrence as well as to lessen their intensity and/or spatial extent) because their future will depend on strategically planned risk management policies. However, the current approach adopted to manage natural risks only focuses on the financial and technical concerns and appears out-of-date. Critics argue that although this strategy may reduce losses in the short term, it has failed to meet this goal in the long term (Degg, 1998; Mileti, 1999) because natural risk is a complex problem that transcends technical and economic issues. A weakness of the traditional way of managing urban natural risks is the static reasoning of most of the methods for assessing management measures impacts while cities are temporal changing areas. Given these observations, innovative substitutes to the technocratic ideology are needed (Mitchell, 1998). A particularly interesting option consists of a comprehensive approach that endows cities at risks with strategic pathways to address sustainability (Degg, 1998; Glavovic, 2010), and the later is an emerging issue in the risk management field.

As sustainability is a term that has quite a broad connotation, there is also fuzziness inherent in the concept of sustainability related to risk management so that interpretations differ for researchers. In practice, sustainability in the context of risk management could mean placing greater emphasis on integrating the profitable results of risk management with the standards of sustainable development of a given territory through a holistic perspective. It includes initiatives, which allow management activities to contribute to the minimisation of risk losses, alleviation of poverty, enhancement of social equity as well as quality of life of people, growth of community engagement and involvement, maintain and improvement of natural resource base as a whole over long periods of time. Therefore, establishing sustainable risk management practices has become necessary (Di Mauro et al., 2006). Accordingly, the traditional risk management approach has been rethought through efforts to integrate non-technical as- pects such as socio-cultural, environmental, and governancerelated issues (Wurbs, 1996; Putri and Rahmanti, 2010).

Addressing the sustainability of risk management activities (prevention, mitigation, response, and recovery) has gathered momentum, as indicated by the numerous studies (see for instance Mileti, 1999; Kundzewic, 2002; Galloway, 2004; Scottish Executive, 2005; Werritty, 2006; Agrawala, 2007; Kang et al., 2013) or initiatives (Hyogo Framework for Action, European Flood Directive, different projects such as FLOODsite, LiveWithRisk, CapHaz, etc.). Its significance has been recognised by several nations (Australia, UK, Germany, Japan, Bangladesh, etc.), and international organisations (United Nations, European Union, Asian Disaster Prevention Centre, etc.) around the world.

Due to this focus on sustainable risk management, managers must be able to measure performance in this area because many studies indicate that sustainability assessment is required to increase the diffusion of sustainable activities and sectors. Measuring the degree of sustainability of risk management activities will focus on the assessment of how effective the goals regarding territorial defence against risk, greater economic dynamism, social justice, and preservation of natural/cultural resources are or will be achieved. Therefore, to foster their efforts to shift toward this new approach, formal appraisal procedures must be introduced to the decision-making process, requiring "the existence of tools, instruments, processes, and methodologies to measure performance in a consistent manner with respect to preestablished standards, guidelines, factors, or other criteria" (Poveda and Lipsett, 2011).

Finding an accurate framework to assess the sustainability level of future and the existing decisions has become an important issue. A review of literature shows that some methodologies and tools are available to assist managers in the sustainable risk management field (Turner II et al., 2003; Freedman et al., 2004; Achet and Fleming, 2006; Kang et al., 2013). However, most of these tools are either specific to a hazard (mostly flood and coastal hazards; see McGahey et al., 2009), based on a mono-criterion approach, considering only one aspect of sustainability (e.g. environmental impact assessment, life cycle assessment, social impact assessment, cost-effectiveness analysis; see Singh et al., 2012), or do not provide specific criteria and/or indicators among the few methods that account for the different aspects of sustainability. At our knowledge, although these tools can guide sustainable risk management, none of them are general, integrated theoretical tools that provide the proper set of criteria and indicators for assessing the sustainability of natural risk management in urban areas (Kundzewicz, 2002).

Even characteristics (physical phenomena, measurement, terms associated with, etc.) differ from one hazard to another; it is helpful to have a commonly adopted scheme for fostering sustainability in the risk management process. Such a scheme must be an inclusive framework, encompassing generic and particular indicators/parameters so that some 
of technical indicators/parameters should be specific to the treated hazard.

The specific purpose is to support sustainable natural risk management by guiding the assessment of potential sustainability during management decisions. This paper, therefore, proposes a methodological and applicative framework that is built from a review of the sustainability literature. Such a framework is supposed to provide key information that will assist decision-makers in choosing the most sustainable risk management decision. This proposal is within the scope of the INCERDD research project (prise en compte des INCERtitudes pour des Décisions Durables) that seeks to provide a methodology that accounts for the uncertainties within the sustainable decisions in urban areas. The content of this paper centres on two key parts. The first part is organized in sequential sections of (Sect. 2) a presentation of the conceptual framework of sustainable risk management, (Sect. 3) a general introduction to multi-criteria decision-making techniques, and (Sect. 4) a description of the proposed methodology. In the second one, there are two sections, which are devoted (Sect. 5) to briefly depict the case study, and (Sect. 6) to comment the results of the case study. Then, some concluding remarks and perspectives for further research are drawn in the last section.

\section{Part 1: Theoretical aspects}

The following sections discuss theoretical aspects surrounding the suggested methodology for assessing the sustainability of natural risk management decisions in urban areas.

\section{Definition and principles of sustainable risk management}

Understanding the sustainable management of risk associated with natural hazards requires foremost the explanation of the key concepts: risk, disaster, hazard, vulnerability, and risk management. Due to the importance of terminology, although there is no single definition for those concepts, the following definitions based on the United Nations Office for Disaster Risk Reduction (UNISDR, 2009) terminology on disaster risk reduction should be adopted in this paper. Risk could be defined as the result of the interaction, in space and time, between hazardous events and vulnerability of the exposed elements of a territorial system. In such an interaction, risk represents the expectation value of potential consequences associated with the occurrence of a given hazard, where the characteristics of the hazard and the vulnerability level of the endangered system determine the types and levels of losses. A risk that occurs may trigger a disaster when local capacity to respond to this risk is overwhelmed and outside assistance is needed. Disaster could be defined as a serious disruption of the functioning of the impacted system due to the amount of damages suffered which exceeds the ability of the system to cope using its own resources.

Hazards, in the context of natural risks, are physical phenomena (single, multiple or concatenated) of natural origin that may potentially cause injury or loss of life, property damage, socio-economic disruption, and environmental deterioration. Floods are the most common and threatening natural hazards for urban areas (Vanneuville et al., 2011). Each year, the greatest natural hazards damages result from flooding: their economic impact is valued in the billions of US dollars annually. Vulnerability of exposed systems to natural hazards is an integral factor encompassing physical, economic, social, political and environmental aspects that allows an understanding of the real extent of risk. It depends both on the exposure of people, their livelihoods, their support infrastructures and services to hazards, and on their tendency (sensitiveness, fragility, lack of resilience) to suffer damage when impacted by hazards. Risk management is a systematic process of preparing a territorial system to cope with the adverse effects of risk through actions for prevention, mitigation, preparedness, emergency response, recovery, and lessons learning through feedback. It includes all policies, strategies, and measures that aim to minimise potential losses by either lessening the intensity as well as the spatial extent of hazards or reducing the vulnerability of the elements at risk.

Nowadays, the challenges for risk-managers are not only to limit the costs of ensuring territorial protection against risk and to reduce the risk to people and their assets; they also relate to the wider consequences of risk management decisions to the people's well-being, the political organisation, and the environment. When considering such neglected aspects, practitioners could make decisions not only based on the effectiveness and economic viability of measures but also on the assessment of environmental, institutional, and social benefits and costs. Where to locate infrastructural projects, how their construction affects land use, ecological system, and public awareness, which institutional functioning and organisational arrangements for their better social acceptance are some of factors that can significantly influence their expected impacts. The added benefits of the sustainable management approach are to avoid the destruction of the socioecological fabric of territories contrary to the current approach that seems to offer less incentive to arouse active participation of defence structures beneficiaries.

While sustainability is becoming a central goal for policies in the risk management sector, there is no common or standard definition of sustainable risk management. Individuals may understand this concept differently. Even in the literature, definitions are scarce. Consequently, because studies of sustainable natural hazard management are usually floodspecific (this broader emphasis is because flooding is the most important and the costliest natural disaster all around the world), we may first refer to the definition given by the Scottish National Technical Advisory Group on Flooding Issues (NTAG). Sustainable flood management is defined as 
a management that "provides the maximum possible social and economic resilience against flooding, by protecting and working with the environment, in a way which is fair and affordable both now and in the future" (Scottish Executive, 2004). Sustainable risk management can be defined as the minimisation of damage caused by natural hazards and/or the enhancement of resilience in both people and buildings toward these hazards to promote economic efficiency, social well-being and equity, as well as environmental improvements in the long term. This general definition is consistent with that adopted by this paper and proposed by Saunders (2010b): sustainable risk management "ought to reduce, or at minimum not increase, community vulnerability and disaster recovery costs to levels that do not compromise other public objectives nor burden future generations". This definition argues that in addition to ensuring risk prevention, mitigation or recovery, the additional consequences of implemented measures also require careful consideration within the complex economic, technological, political, social, and environmental urban aspects (Kenyon, 2007).

Therefore, this paper adheres to the principles guiding sustainable risk management processes that were proposed by Mileti (1999) regarding the key components for sustainable hazard mitigation: (1) maintaining and enhancing the environment; (2) maintaining and enhancing the quality of life; (3) fostering local resilience toward and responsibility for disasters; (4) recognising that vibrant local economies are essential; (5) identifying and ensuring inter- and intra-generational equality; and (6) adopting a consensus-building approach beginning at the local level through local participation.

Specifically, any sustainable management measure requires an interdisciplinary analytical and operational approach that must be combined with a more flexible and participatory institutional framework and involve a wider range of stakeholders. This approach also requires better reversibility, common acceptance, and environmental friendliness (Kundzewicz, 2002). Furthermore, this approach considers the historical and institutional perspectives, as well as the socio-economic, environmental, and cultural aspects (Turner et al., 1999). Alternative strategies should focus on reducing natural hazard losses and contribute to the broader goal of sustainable development (Klijn et al., 2009).

The ultimate goal for every sustainable risk management process is to maximise the outcomes because the losses due to natural disasters increase due to human decisions and investments (Hansson et al., 2008). Consequently, this paper introduces a methodology based on an indicator-based tool for examining whether risk management strategies will point toward sustainability during the decision-making process.

\section{Multi-criteria decision-making techniques}

Decision-making is supported by several techniques classified in two main categories: single criterion (e.g. costbenefit analysis), and multiple criteria (e.g. multi-criteria decision analysis, hereinafter MCDA) techniques. The latter are used when dealing with complex decisions. MCDA guides decision-makers "through an evaluation of potential decision options using explicit profiles of their advantages and disadvantages across a range of distinct dimensions" (Dolan, 2010). MCDA consists of a set of methods that typically aim at structuring and simplifying complex problems, facilitating dialogue between stakeholders, and legitimising the final decision (Roy, 2005). Carrying out MCDA obeys the following basic path: (1) establish the decision context; (2) specify evaluation criteria/sub-criteria; (3) identify alternative options; (4) calculate a total performance (including scoring, weighting, aggregation) for each option; and (5) rank options accordingly (Farley et al., 2005).

Sustainable natural risk management is a multidimensional concept that involves a number of stakeholders with multiple conflicting objectives or priorities. Using MCDA, a well-acknowledged sustainability assessment technique, will help make better choices when facing such a management decision. However, there are several MCDA methods (analytical hierarchy process - AHP, ELECTRE, MACBETH, multi-attribute utility theory - MAUT, PROMETHEE, TOPSIS, etc.), and each of them summarises final results differently. According to the underlying decision rule or theory, some methods indicate an optimal option (optimisation), while some rank options through a pairwise comparison regarding each criterion (outranking), and others identify acceptable or non-acceptable options (aspiration- or goal-oriented perspectives). Choosing one method instead of another depends on users' requirements and expectations, as well as on the method ease of understanding. The easier it is to understand the method, the better decision-makers will use it.

This paper attempts to offer a framework to sustainable risk management decision-making on the basis of an MCDA conceptual scheme without making the choice of a specific MCDA method. Thus, it is elaborated to be simple, easy to understand, and generic to allow all underlying decision rules ensuring its suitability to assess the sustainability of natural risk management decisions in any context.

\section{Methodology for assessing the sustainability of risk management}

Sustainability assessment helps to evaluate sustainability level in risk management policies. It is an important tool in estimating overall possible consequences of projected management decisions on local sustainable development. Sustainable assessment advises decision-makers on what 


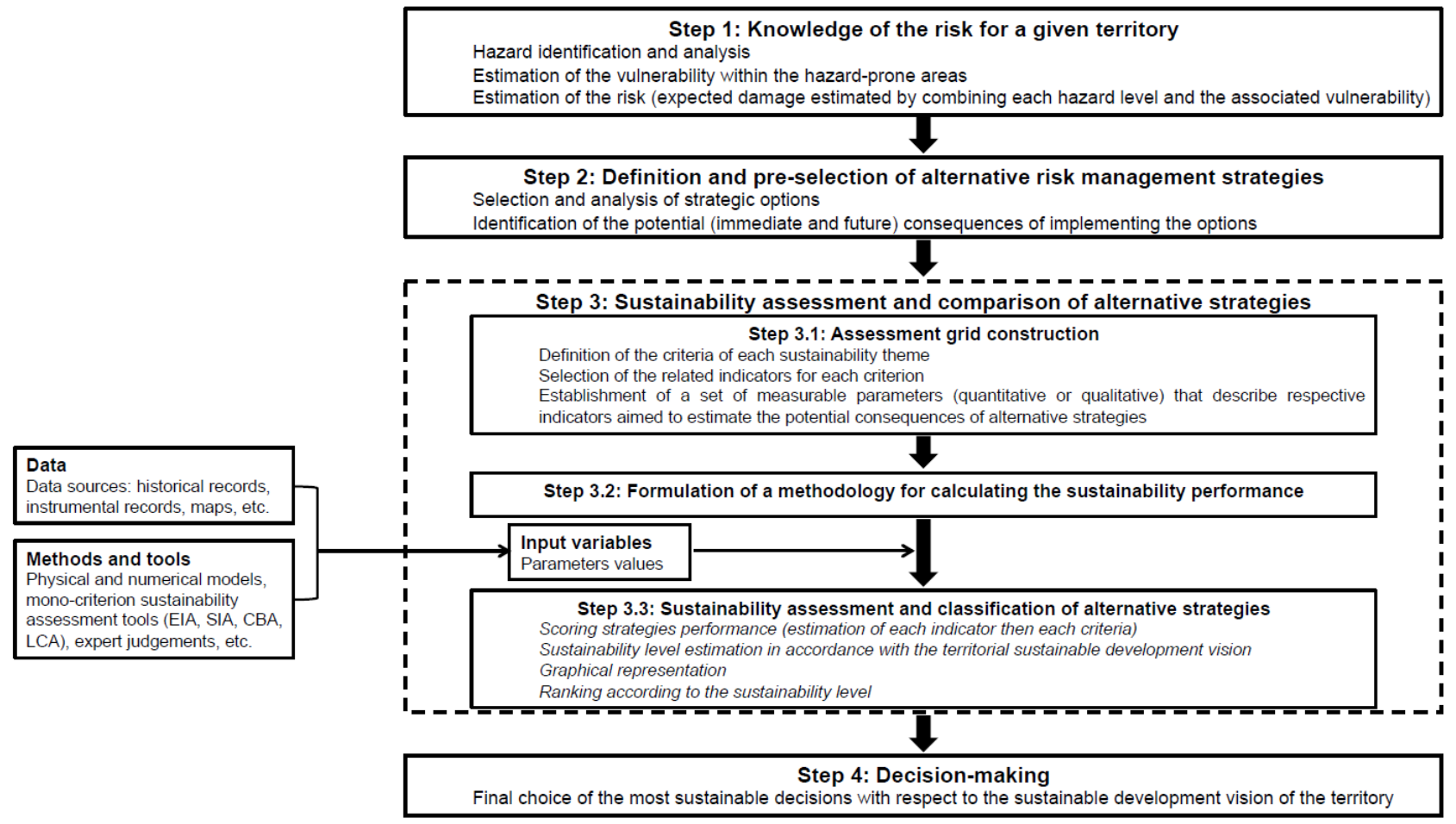

Figure 1. Theoretical overview of the decision-making process for sustainable risk management (source: authors).

decisions should (or should not) be adopted, and under what conditions.

As illustrated in Fig. 1, the standard approach to sustainable decision-making may be outlined as a sequential process with four major stages. Moreover, to support successful decisions regarding risk management needs, among other requirements, "a common conceptual framework which seeks to understand and formalise the full range of issues that stakeholders may pose" and "a supporting methodological framework which is a translation of the conceptual framework into an analysis process containing tangible algorithms, methods and model interactions" must be introduced (McGahey et al., 2009). Therefore, the suggested evaluation framework should represent the third stage, and its construction can be subdivided into three tasks: (1) selecting sets of criteria and indicators, (2) formulating a methodology to evaluate the sustainability performance, and (3) defining decision rules for selecting the most sustainable decision.

The methodology followed in this paper is based on a literature review of the indicator-based approaches for sustainability assessment, as described below after specifying some methodological choices. These choices concern the relevant spatial and temporal scales considered during the sustainability assessment while using this tool.

\subsection{Spatial and temporal scales}

Spatial and temporal scales are very important when "attempting to put sustainability into practice, or in gauging the level of sustainability" (Ko, 2005).

The diverse spatial scales have different specific factors that influence the risk management decision process. According to Graymore et al. (2010), the current sustainability assessment methods used at the global, national and state scales are not entirely effective at fulfilling their goal, according to these spatial scales. The indicators are defined on the chosen spatial scale, and they capture only synoptic aspects for the scale on which they are applied.

As territory is a hierarchical structuring system with different spatial scales (neighbourhood, municipality, county, region, nation) delineated by their administrative boundaries so that risks of natural origin are nested at those various levels, it is crucial to specify on which scale sustainability of the management is to be evaluated (Fekete et al., 2010; Kienberger et al., 2013). According to their specific characteristics, each scale (micro-, meso-, and macro-levels) has to be treated separately: a variable with specific strength at one scale could seem inappropriate at another. For instance damage estimation mainly relies on assets typology at micro level and land use at meso-level. An explicit description of the spatial scale in the conceptualisation of the methodology helps to identify accurate sustainability indicators/parameters, to determine how indicators/parameters on different levels can 
benefit from each other, and to detect which constraints of data collection have to be faced. In general, the preciseness of analysis increases at small scale and is more generalised towards the more aggregated scale.

It is observed that small-sized hazardous events are more frequent, as consequences it is at the fine spatial scale where theorising a methodology becomes useful for risk-managers. Hence, this paper uses municipalities, which are a smaller urban spatial unit, as a meaningful or suitable scale that could lead to a more accurate framework and assist the further adaptation and application to the other spatial scales. The focus is on typical French communities with less than 2000 people (INSEE) ${ }^{1}$ and an average area of approximately $20 \mathrm{~km}^{2}$.

According to Fekete et al. (2010), in comparison to the upper scales the main pros of this scale are more detailed information, a better capture of complexity of phenomena, the use of participatory methods for data collection, a higher availability of data related to one item, a lower level of uncertainty, etc. Contrariwise, it is limited by loss of information while up-scaling the assessment.

Concerning the temporal orientation, this framework obeys a prospective logic because it is designed for ex ante assessments of decisions; it might be used to examine the sustainability of existing management measures. Because the consequences and impacts of decisions can vary over time, their sustainability must be assessed on different temporal scales. Some effects can occur immediately after implementing the decision or only after a longer or shorter interval. First, this paper argues that the temporal scale should involve the entire life or mission span of the risk management decisions. Second, planning those decisions within the context of sustainability entails planning beyond 50 or 100 years (Saunders, 2010a), requiring plans for future generations. Indeed, the decisions "should not only be taking short- and mediumterm into account but also the (very) long-term, thus leading to more sustainable risk decisions" (Genserik, 2012).

Building on the evidence that accounting for different temporal perspectives can improve the level of sustainability, this framework is intended to address the assessment as a continuum (ranging from the short to the long term) when predicting the variability of the sustainability over time. This tool should facilitate strategic planning within sustainable risk management in the long term while considering the dynamic behaviour of the factors that affect the sustainability over time, such as the expected territorial dynamic; this factor helps determine the future of the territory and establish risk management requirements. In the case study, only one timescale assessment was undertaken. However, several timescale assessments should be performed in practice to appraise the evolution of the sustainable strategies over

\footnotetext{
${ }^{1}$ According to the INSEE (Institut National de la Statistique et des Etudes Economiques), the average population of the most of French communities is about 1750 inhabitants on 1 January 2008.
}

time and to determine the most sustainable decision over time, thereby generating relevant sustainable decisions for the future.

\subsection{Criteria identification and indicators selection}

The main objective is to elaborate an indicator-based grid. Criteria and indicators can be selected using a top-down or a bottom-up approach (Franco and Montibeller, 2009; Weiland et al., 2011). Both approaches involve decomposing a complex decision into a hierarchical structure that represents the sustainability performance and is built from the input variables situated at the bottom level of the pyramid.

The top-down method is used to break down the sustainability concepts into dimensions, criteria and indicators. This deductive approach facilitates the following: the theoretical description of the objectives and the rigorous collection of the corresponding criteria and indicators from the literature. This approach should ensure that the correct conceptual information is retained with the common criteria and indicators of generic sustainability.

The bottom-up approach is used to select criteria and indicators that match the contextual requirements from the specific field whose sustainability will be assessed. This inductive approach is often rooted in the concerned field and aims to ensure that specific information related to the field at hand is accounted for. It starts with the identification of the potential consequences and effects of the field. Once the set of consequences and effects is defined, they can be grouped into indicators based on similarities. Indicators can then be grouped into criteria. Finally, the criteria can be grouped into objectives. The potential consequences and effects serve as benchmarks for the validation of which indicators and criteria are suitable to fulfil the sustainability concerns of the targeted field.

In this paper, a hybrid approach has been applied, complementarily combining bottom-up and top-down approaches. The process used to construct the assessment grid involves three steps. The first step involves identifying the criteria based on the objectives of sustainable risk management. The top-down approach was applied to identify the appropriate criteria using a combination of the principles for sustainability assessment (Gibson et al., 2005; Gibson, 2006) and those for achieving sustainable risk management Mileti (1999). The following five criteria were proposed:

- Technical and functional effectiveness addresses the capability of measures to fulfil the primary function of risk management, providing protection against natural risks and reduce losses from those risks.

- Economic sustainability is used to obtain the most out of measures with fair economic outcomes (efficiency and affordability). 
- Social sustainability addresses the social and societal aspects, such as the community benefit and fair distribution/contribution.

- Environmental sustainability assesses the implementation of measures relative to all species, habitats, and landscapes.

- Institutional sustainability addresses the issue of governance (norms, values, and practices).

The second step concerns the identification and selection of performance indicators that highlight the different aspects of sustainable natural risk management depicted by the five criteria. Sustainability indicators depend strongly on their target field. In this paper, they were suggested according to their ability to describe the pressures of risk management on urban sustainability. The "urban areas" focus of this paper involves identifying an explicit set of technical, economic, social, environmental, and institutional performance indicators, which are able to address urban concerns. Even if each city has its specific characteristics, most cities share some common concerns such as unemployment, energy efficiency, housing, governance, transportation, social cohesion, environmental improvements, etc. Typically, regarding natural risks management, these concerns must include land use typology (residential, commercial, recreational, industrial parcels) and planning, housing typology (individual or multi-family houses, detached or semi-detached houses), social characteristics of population affected by hazards (age, disability, gender, socio-economic status, ability to recover from a shock), social amenities (schools, hospitals, green spaces) availability and accessibility, etc. Sustainable natural risk management in urban areas aims to identify what aspects of the risk management agenda have implications for urban sustainable development, and to reconcile those aspects with policies for addressing urban sustainability.

The bottom-up approach was exhaustively applied when inventorying the potential (direct and indirect, as well as tangible and intangible) effects and consequences (pros and cons) of risk management decisions over periods that are much longer than the lifetimes of the investments. For the natural risk management policies, the potential consequences could include a decrease/increase in casualties and disabilities (direct), a decrease/rise in economic activity (indirect), continuing damage to assets due to the residual ${ }^{2}$ risk (tangible), impacts on human health or natural resources and functions (intangible), increased public awareness of local natural hazards (pros), or a transfer of risks to another area (cons). Furthermore, some policies may have positive future consequences, but their immediate consequences could be negative, or vice versa. For instance, the development level of a territory might be improved in the future, but there may be significant implementation costs on the short-term scale.

\footnotetext{
${ }^{2}$ The residual risk is the irreducible portion of the risk associated with the potential implementation of management solutions.
}

These potential effects have shown which considerations are important while assessing risk management decisions; these effects were explored to identify the relevant indicators. Once these effects and consequences were identified, a literature review was completed and a set of potential indicators was created according to their relevance regarding the studied field and based on an overview of existing national and international sustainability assessment methodologies (Singh et al., 2012) and tools.

No specific indicators exist for evaluating the risk management that are universally or widely accepted (Carreño et al., 2007). Therefore, indicators were selected from various tools used to gauge sustainability in various fields. These tools are Sustainability Reporting Guidelines G4 provided by the Global Reporting Initiative, RST02 grid (France), "Boussole 21" grid (Belgium), International Urban Sustainability Indicators List (IUSIL), the reference framework for European sustainable cities, Sustainable Transportation Performance Indicators (STPI), and risk management performance criteria proposed through the action framework led by the International Strategy for Disaster Reduction (ISDR). Amongst those tools, only two refer clearly to natural risks, without making special indication on the type of natural hazards. The IUSIL considers "natural hazards" as an indicator of social criteria when assessing urban sustainability, and the ISDR framework provided a set of goals and criteria for guiding, and monitoring disaster risk reduction. These two tools could be adapted to any natural hazard by defining specifically relevant indicators or parameters.

Finally, using a collaborative and multi-disciplinary process, researchers involved in the INCERDD project shared their knowledge, experience and judgements to validate the set of the proposed indicators with regard to their relevance, applicability and other characteristics, such as measurability and accessibility to those without specific knowledge. Indeed, as the main target of indicators is to reduce the complexity of information needed by decision-makers, they should be "measurable, scientifically valid and capable of providing information for management decision-making" (Donnelly et al., 2007). Sustainability indicators have to fulfil the following requirements. They have to be: (1) relevant by showing what is essential to be known, (2) easy to understand by every actor of risk management even if he is not an expert, (3) reliable so that the information they provided will be trusted, and (4) based on accessible data so that the information will be available when it is needed. However, indicators "can be developed independently of available datasets" (Donnelly et al., 2006) and doing that could help drive production of needed data.

The experts, when selecting the components of the proposed grid, checked all the retained indicators in the light of those requirements. Indicators were retained when they meet the majority of criteria (that is to say three), which inevitably include the criterion "relevant" expressing the importance of the indicator in relation to sustainable risk management. 
Although it was difficult for every indicator to conform to all of these requirements, it was important that they complied as much as possible. For instance, some effects and aspects seem to be significant but remain difficult to assess, particularly regarding the social and institutional dimensions (Lekuthai and Vongvisessomjai, 2001 cited by Poulard et al., 2010). Because some of the indicators are related to intangible concerns (e.g. recreational value, quality of life), the analysis is very complex; these indicators are often assessed based on subjective assumptions. Subsequently, their estimation causes several problems, such as finding consensus on the parameters and how to measure these factors concretely.

The obtained sustainability assessment grid is constructed using a hierarchical structure that includes seventeen contextspecific indicators. This grid is schematically depicted in Fig. 2 and assumes that qualitative indicators ${ }^{3}$ might include numerous sub-indicators called parameters that would enable their assessment. Parameters are the measurable or observable variables that describe the corresponding indicator (Bragança et al., 2010). In accordance with the sequence of tools through which impacts of a plan or policy can be measured (Donnelly et al., 2006), and in the hierarchical structure of the proposed assessment grid, criteria represent "objectives", indicators represent "general targets" while parameters are the simplest measurable features that can be used to assess and monitor a performance. Commonly indicators are composite indices made of a wealth of complex and detailed information aggregated in unique understandable information.

Parameters can be identified and selected on a case-bycase basis by relying on the distinctive characteristics of the territory and its prevailing sustainable development targets. Although the objective of this paper is to provide a more precise and defined framework to assess the sustainability of risk management initiatives, the parameters were informally selected. This choice might render the framework more flexible by allowing to users to propose better parameters depending on their particular context, the specific purpose of sustainable development in their urban setting, and data availability.

Even though none of the proposed criteria and indicators is absolute, they were chosen from different domains according to key considerations briefly depicted as follows. The criterion "technical and functional effectiveness" aims to help measure a decision success in achieving damage limitation. To attain this objective, it seems appropriate to consider as indicators, hazard characteristics (intensity/magnitude, spatial extend, frequency, speed of onset, etc.), structural or physical vulnerability (typology, value and sensitivity of exposed assets), and the potential of the decision to create or exacerbate existing or new risks (both hazard and vulnerability measuring variables). The criterion "economic sustainability" intends to estimate decisions impacts on the economic productivity of the territory. The success of a strategy in en-

\footnotetext{
${ }^{3}$ The indicators are not necessarily split into parameters; some parameters might be split into sub-parameters.
}

abling continued economic growth while reducing natural risks damages could be checked with indicators such as its costs, its potential avoided damages, and its ability to create or not economic value for society.

The objective of the criterion "environmental sustainability" is to appraise the capability to preserve and maintain ecological heritage. Related general targets are, at one hand, to reduce environmental vulnerability to risk, and at the other, to avoid strategies that would induce significant adverse effects on ecological heritage. Thus, the retained indicators are: "impact on the environmental vulnerability" and "environmental impacts". To select the parameters on which the indicator "impact on the environmental vulnerability" can be split to, the stakes that, when situated in hazard prone zones, could contribute to the environmental sustainability of a territory were identified. Possible features to consider are: areas of protected natural habitats, sites with pollution potential, drinking water sources, wastewater treatment plants, volume of wastes probably resulting from risks that need to be disposed of, etc.

The criterion "social sustainability" could be split into various indicators expressing general targets related to social conditions of people. For the general target of enhancing "quality of life", some measurable features or parameters could be: average travel time/distance to work/amenities (to show transportation trends induced by the decision), number of amenities such as shops, health care centres, recreational public spaces, etc. (because urban amenities facilitate social contact), etc. The indicators and parameters associated with "institutional sustainability" help check whether the management strategy is at the expense of another community sustainability, and if the decision-making process will actively involve stakeholders.

The multidisciplinary approach developed through INCERDD project help ensure less bias in the decision-making process by encompassing all dimensions of sustainability with a broad spectrum of influential variables. These suggested indicators should be a reference for public institutions and the private sector when making sustainable natural risk management decisions. The suggested indicators are not exclusive and should be treated as an indicative checklist of which issues to consider at a minimum when assessing possible solutions with a focus on sustainability. However, one of the challenges remains rendering the grid operational. To address this issue, the following subsection focuses on formulating a methodology to assess the sustainability performance using the grid.

\subsection{Sustainability performance assessment}

Once the indicators were selected, they needed to be quantified or qualified depending on their quantitative and qualitative nature. Sustainability indicators of natural risk management can be either quantitative (e.g. number of residential buildings within the hazard prone area) or qualitative 


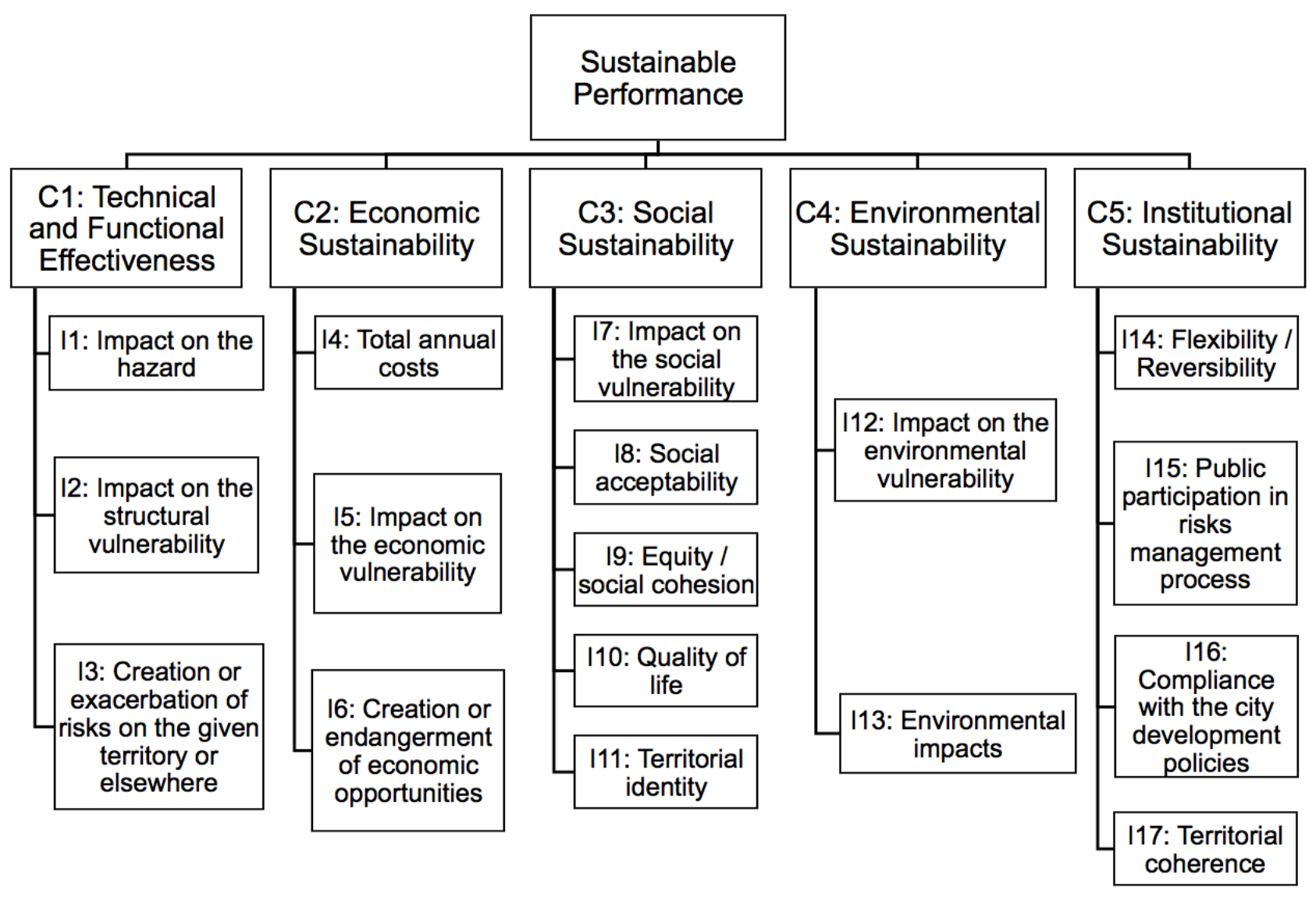

Figure 2. Hierarchical structure of the sustainability assessment grid (source: authors).

(e.g. level of recovering from disruptions). The latter may be more suitable for intangible aspects like social, and cultural concerns. For instance, "social acceptability" could be considered as a qualitative indicator, which depends on considerations such as preferences of people with regard to risk management issues, perceived fairness of decisions impacts, stakeholders' willingness to support constraints (in terms of financial costs, consistency with social customs, etc.) from decisions. Both of the two types needed to be calculated differently. Quantitative indicators provide information using numbers: they can be evaluated directly from the available data related to measured amounts or from modelling. Qualitative indicators provide information as a description using words: they could be evaluated based on a comparison to a system of references, description, perception or judgement regarding their relative importance when accurate data are limited. The obtained descriptions can then be numerically scaled using different scaling techniques (e.g. codes, matrices).

As asserted by González et al. (2013), "successful decision support tools provide information in a concise relevant format in order to inform decision-making processes". To fulfil this objective, a sequenced, understandable and easy-to-use methodology should be used to evaluate different strategies during natural risk management. For a better understanding of each step of the methodology, the paper presents a pedagogical example to illustrate calculations regarding each equation. This example serves also as case study to demonstrate how the whole methodology may be used as decisionsupport tool for selecting the most sustainable risk management decision.

Assuming that the input data ${ }^{4}$ of the methodology are the parameter values (when dealing with quantitative indicators) and the indicators values otherwise, the calculation process follows almost the steps of the OECD methodology for building composite indices (OECD, 2008) because indicators and criteria are composite indices. Standard procedures such as choosing a representative series of sub-indices (parameters, indicators), verifying whether normalisation is needed and with which method, dealing with weighting concerns, how to

\footnotetext{
${ }^{4}$ The data sources (e.g. historical records, instrumental records, maps) and various methods/tools (e.g. physical and numerical models, existing mono-criterion sustainability assessment tools, expert judgements) might be used to generate input data. This framework does not indicate which methods/tools to use; the primary purpose is to generate the required input data.
} 
aggregate sub-indices were applied. No assessment of multicollinearity among the sub-indices has been done to check if there are correlations between them. Nonetheless, users have to selects parameters in a way to combine or eliminate those, which could be collinear.

While operating the methodology, users could make data screening tests (removing outliers, identifying erroneous data values, detecting missing data, etc.). Indeed, the problem of input data availability is crucial because in reality there will inevitably be some missing data. It is necessary to supplement missing data, if it is possible. An option is simply to exclude the parameters that are suffering missing data from the set of parameters for all the assessed alternatives. Failing that, users could solve this problem through several missing data imputation procedures. They could build plausible data according to similarities of the study case with other cases (external sources) or based on imputation methods such as mean - median - mode substitution, nearest neighbour interpolation, various regression techniques, etc. (OECD, 2008; Glasson-Cicognani and Berchtold, 2010). Although imputation can help minimise bias, it should always be kept in mind the incompleteness of data because imputed data are not real data. Given this background, the suggested sustainability assessment methodology is organised as follows.

\subsubsection{Definition of reference values}

Sustainability assessment can be performed through two main approaches, one based on a relative evaluation, and the other on an absolute evaluation. The values of the parameters or indicators are not able to reveal by themselves the sustainability performance level of a decision; a comparison with reference values provides this information (Tugnoli et al., 2008). This process requires reference values to which each parameter/indicator value can be compared. Several values could be taken as reference:

- The desired level of sustainability value for each parameter/indicator should be included (Van Cauwenbergh et al., 2007). This value could be established on empirical, regulatory, or scientific basis in accordance with the related field, and specificities of the territory (AcostaAlba and Van der Werf, 2011).

- The fixed thresholds may be expressed either as lower, higher or ranges of acceptable values that should not be exceeded (Wiek and Binder, 2005; Zahm et al., 2006). They may be normative values based on legal or scientific norms or expert judgements derived from observations related to the parameters.

- The value for each parameter/indicator resulting from a reference situation that is often the baseline policy considered as the status quo or do-nothing alternative, assuming that no new measures are taken (Klijn et al., 2009).
It is important to clearly define the reference values because there is a linkage between the assessment approach and reference values type. An absolute assessment is based on what is understood by sustainable development (ideal values and/or fixed targets) while a relative one is based on a given situation. The suggested methodology adopts a relative approach. It relies on the estimation of the variation resulting from the studied alternatives compared to the existing natural risk management policy.

\subsubsection{Estimation of performance at parameters level when dealing with quantitative indicators}

For the quantitative indicators, this estimation consists of three steps. The first step includes the calculation describing the expected performance of a given option in the context of a specific parameter. Equation (1) can be used to assess whether the option is better/worse than the reference situation or contributes to/conflicts with the target/threshold regarding the considered parameter.

$V_{\text {dif }}=V_{\text {opt }}-V_{\text {ref }}$

where $V_{\mathrm{dif}}, V_{\mathrm{opt}}$ and $V_{\text {ref }}$ are the potential performance, the parameter value for the analysed option and the parameter value for the reference situation, respectively.

The second step involved in the calculation of the impact rate or the degree of convergence/compliance to the target/threshold (ImpR). This value represents the ratio ${ }^{5}$ between the potential performance $\left(V_{\mathrm{dif}}\right)$ and the reference value $\left(V_{\text {ref }}\right)$, as shown in Eq. (2). This step produces the relative impact values expressed as percentages and enables the relative values to be combined with several quantitative parameters that are no longer defined by their own specific measurement units. The normalisation of the potential performance reveals the magnitude of impacts in relation to the reference value for each parameter (Myllyviita et al., 2014).

$\operatorname{ImpR}=\frac{V_{\text {dif }}}{V_{\text {ref }}}$

Assuming that for a given alternative option, a parameter value $V_{\text {opt }}$ is 21 while reference value $V_{\text {ref }}$ is 13 , the ImpR of this alternative relative to the parameter equals $+61.53 \%$.

The third step consists of assigning a value score (ImpS) to each impact rate (ImpR) according to its level and its nature (advantage or disadvantage); this process generates ordinal numerical values, facilitating aggregations and simplifying the assessment process (Gafsi and Favreau, 2013). The scoring could be performed using a bidirectional ${ }^{6}$ Likert-type

\footnotetext{
${ }^{5}$ To simplify the calculations, when the reference value $=0$, the following are true: the value of the impact rate $(\operatorname{ImpR})=0 \%$ when the alternative value $=0$; the value of the impact rate $= \pm 100 \%$ when the alternative value $\neq 0$.

${ }^{6}$ The plus and minus signs indicate whether the studied option has a positive or negative incidence compared to the reference.
} 
Table 1. A nine-point scale for scoring quantitative impacts.

\begin{tabular}{llrlr}
\hline $\begin{array}{l}\text { Impact rate (ImpR) } \\
\text { value range }\end{array}$ & $\begin{array}{l}\text { Positive } \\
\text { impact }\end{array}$ & $\begin{array}{r}\text { Impact } \\
\text { score }(\mathrm{ImpS})\end{array}$ & $\begin{array}{l}\text { Negative } \\
\text { impact }\end{array}$ & $\begin{array}{r}\text { Impact } \\
\text { score (ImpS) }\end{array}$ \\
\hline ImpR $>0.75$ & Very high advantage & +4 & Very high disadvantage & -4 \\
$0.75 \geq \operatorname{ImpR}>0.5$ & High advantage & +3 & High disadvantage & -3 \\
$0.5 \geq \operatorname{ImpR}>0.25$ & Medium advantage & +2 & Medium disadvantage & -2 \\
$0.25 \geq \operatorname{ImpR}>0$ & Low advantage & +1 & Low disadvantage & -1 \\
ImpR $=0$ & Nil impact & 0 & Nil impact & 0 \\
\hline
\end{tabular}

Source: authors.

scale whose range captures the perceived sensitivity of the parameters. The higher the range of the scale ${ }^{7}$, the more sensitive the parameters are. Therefore, using different rating scales might be possible during the same assessment. In this situation, the assessors should ensure a link between the scales, thus facilitating the subsequent calculations. Table 1 presents a nine-point scale. At the central point, zero indicates that the alternative has no effect (neither obstructs or supports sustainability attainment). Positive values express different levels of supporting sustainability fulfilment; negative values reveal grades of its obstruction. According to the aforementioned example and the scale shown in Table 1, to the ImpR with a value of $+61.53 \%$ corresponds an ImpS equals to +3 because impacts induced by the alternative are beneficial $(+)$ and they belong to the interval $] 0.5 ; 0.75]$.

The choice of the length of the scale is important because the sustainability performance can vary with the scale used to assess it. For instance, consider two options A and B with impact rates of -19 and $-9 \%$, respectively. Based on a nine-point scale (isometric units of $25 \%$ ), both impact scores equal -1 , while a twenty-one-point scale (isometric units of $10 \%$ ) will assign an impact score of -2 to option $\mathrm{A}$, and an impact score of -1 to option B. Ceiling effects should be considered due to the context of study cases, and the level of preciseness that is expected. Using long scales (small units) might provide more accurate and refined results than short scales, even if performing the calculation using the latter is much easier.

Using the same range might be possible; however, the length of units must be adjusted according to the sensitivity of the parameters. For instance, when handling a more sensitive parameter, instead of using a fixed length between running scores (isometric units), a different length could be applied from one score to another. To illustrate such a possibility, for a

- very high impact: $\operatorname{ImpR}>0.75$ (low sensitivity) or $\operatorname{ImpR}>0.3$ (high sensitivity)

\footnotetext{
${ }^{7}$ The number used for the scale points is derived from a percentile value for the impact rate; this value might be 9 (fixed length of $25 \%$ ), 11 (length of $20 \%$ ), or 21 (for $10 \%$ ), etc. The scoring scale depends on the context of the study and might influence the overall sustainability rating.
}

- high impact: $0.75 \geq \operatorname{ImpR}>0.5$ (low) or $0.3 \geq \operatorname{ImpR}>0.2$ (high)

- medium impact: $0.5 \geq \operatorname{ImpR}>0.25$ (low) or $0.2 \geq \operatorname{ImpR}>0.1$ (high)

- low impact: $0.25 \geq \operatorname{ImpR}>0$ (low) or $0.1 \geq \operatorname{ImpR}>0$ (high)

- nil impact: $\operatorname{ImpR}=0$ (low or high sensitivity)

\subsubsection{Estimation of performance at quantitative indicators level: aggregation of the parameters}

There exist many aggregating methods within the MCDA approach (e.g. weighted sum, weighted arithmetic mean, weighted product, weighted geometric mean, noncompensatory outranking methods) and there is a lack of objective criteria for adopting an appropriate one (Zhou et al., 2006). However, the two most commonly used aggregating methods for constructing the composite indexes are weighted arithmetic and weighted geometric means (Juwana et al., 2012). The core difference between these methods is that the geometric approach takes into account the differences in the sub-indexes, while the arithmetic aggregation does not do so and therefore creates perfect compensability among all sub-indexes.

The aggregation of the impact scores for the parameters with those for the synthetic indicators reduces the amount of information provided to the decision-makers, thereby simplifying the comparison of the performance of the evaluated alternatives and facilitating the ranking process. In this paper, this aggregation was achieved using the weighted arithmetic mean of the impact scores related to each indicator. This method was chosen because, in contrast to the weighted geometric mean, sub-indexes do not have to be strictly positive. The use of the geometric method under the proposed scheme needs to transform all impact scores for parameters into positive values. Since this methodology is tailored to public use, the aggregation of sub-indexes should be kept as clear as possible. In this sense, the weighted arithmetic mean that is simple and easy to understand was chosen, although it assumes that there is complete compensation among the performance of the parameters/indicators. 
The calculation for the indicator performance index (IPI) is shown in Eq. (3) (where $x_{i}=$ weight of the parameter $i$ ).

$\mathrm{IPI}=\frac{\sum x_{i} * \operatorname{ImpS}_{i}}{\sum x_{i}}$

Parameters are weighted according to their relevance and setting the weight of each parameter is inconvenient. The weighting is critical because the weight of parameters is essentially a value judgement that depends on the context of the risk management project, the sustainability priorities of the territory and the relative importance of each parameter within the composite indicator value. Higher weights are assigned to the most important parameters (Bragança et al., 2007). However, when information regarding the preference of parameter or indicator over another is unavailable, assigning equal weights seems to be the norm (Zhou et al., 2007).

Therefore, while using this framework, the decisionmakers must assign weights to the parameters or indicators that account for the specific needs and societal preferences of the territory. Monetising (willingness to pay, budget allocation process, etc.), and rating (distance to targets, panel methods for eliciting preferences such as analytic hierarchy process) are the two main approaches that can be used to set weighting factors. Instead of using a proper weighting process, decision-makers could refer to generic sets of weights, which belong to recognised schemes or are taken from previous studies or are derived from relative importance of specific concerns, leading thereby to less subjectivity and more transparency.

For the indicator named "impact on the environmental vulnerability", parameters weights may be derived from the territorial coherence scheme (schéma de cohérence territoriale - SCOT) according to the prioritized environmental issues for the given territory. The SCOT is a French document describing urbanism that allows municipalities in a given territory to remain consistent in their policies between various areas to achieve sustainability. This document integrates an environmental diagnostic and an impact assessment regarding environment to underline and rank the stakes. An example could be found at http://www. developpement-durable.gouv.fr/IMG/pdf/F12_MEDDTL_ Fiches_Guide_Ev_Env_Doc_Urba_BD_nov2011.pdf, (MEDDTL, 2011). Parameters related to "environmental impacts" can be aggregated using the weights provided by environmental rating systems, such as the Leadership in Energy \& Environmental Design (LEED) system, while analysing structural alternatives. LEED is a scoring system developed by the US Green Building Council to evaluate the environmental friendliness of buildings.

Once the impact scores for parameters have been quantified, they are aggregated to obtain a composite index that summarises the performance of each indicator. Aggregation involves joining many individual values to form a more cohesive and concise value. When assessing sustainability, aggregation may occur in sequential stages to gather the perfor-
Table 2. A sample of qualitative impacts scoring matrix.

\begin{tabular}{lrr}
\hline \multicolumn{2}{c}{ Impact score (ImpS) } & \\
\hline Impact & $\begin{array}{r}\text { Positive } \\
\text { impact }\end{array}$ & $\begin{array}{r}\text { Negative } \\
\text { impact }\end{array}$ \\
level & 0 & 0 \\
Negligible impact* & +1 & -1 \\
Low impact & +2 & -2 \\
Medium impact & +3 & -3 \\
High impact & +4 & -4 \\
Very high impact & +
\end{tabular}

* Negligible impact is an impact expected not to occur. Source: authors inspired by the work of Zihri (2004) and Mdaghri (2008).

mance of the parameters and obtain the performance of the indicators; the latter are then combined to obtain the criteria indexes.

\subsubsection{Estimation of performance at qualitative indicators level}

When a quantitative impact assessment is impossible ${ }^{8}$, a qualitative assessment might be conducted using various methods based on expert judgements, subjective information, scientific, or legal references. When utilising qualitative data, ordinal scales are routinely used for conversion into numbers. Therefore, the qualitative indicators can be scored using the fully described level of the estimated consequences of a decision through assessment matrices, rating scales, and scorecards. Their construction must be of a meaning in order to precisely justify scores awarded. They should be clearly understandable, and should explain under which circumstances an option will get a certain score or how to fill them in; even if experts, which assign notes, are supposed to be people possessing knowledge in this specific field.

Regarding a nine-point bidirectional scale, Table 2 shows an example of a simplified matrix for assessing the qualitative impacts within the developed framework. The scores are assigned based on a -4 to +4 scale, referring to the quantitative impact scores scale presented above (Table 1). As for the quantitative parameters, assessment matrices could also capture the sensitivity of parameters. Table 3 shows an example of a possible interaction matrix between impact level and indicator sensitivity. After granting a score to each qualitative indicator, the indicator performance index (IPI), which expresses the marginal impact of options relatively to the reference situation, is directly obtained by subtracting the score of the option under study $\left(V_{\mathrm{opt}}^{\prime}\right)$ from the score of the reference situation $\left(V_{\text {ref }}^{\prime}\right)$ as shown in Eq. (4).

IPI $=V^{\prime}{ }_{\text {opt }}-V^{\prime}{ }_{\text {ref }}$

\footnotetext{
${ }^{8}$ This situation occurs for some of the parameters for the selected indicators
} 
Table 3. A sample of qualitative impacts scoring matrix based on the sensitivity of the indicator.

\begin{tabular}{|c|c|c|c|c|c|c|c|c|c|c|c|c|}
\hline \multirow[b]{3}{*}{ Impact level } & \multicolumn{12}{|c|}{ Sensitivity of indicator } \\
\hline & \multicolumn{4}{|c|}{ Low to Medium } & \multicolumn{4}{|c|}{ Medium to High } & \multicolumn{4}{|c|}{ High to Very High } \\
\hline & Low & Medium & High & Very High & Low & Medium & High & Very High & Low & Medium & High & Very High \\
\hline $\begin{array}{l}\text { Impact level based } \\
\text { on sensitivity }\end{array}$ & Low & Med. & High & Very High & Med. & High & Very High & Very High & High & Very High & Very High & Very High \\
\hline Impact score (ImpS) & \pm 1 & \pm 2 & \pm 3 & \pm 4 & \pm 2 & \pm 3 & \pm 4 & \pm 4 & \pm 3 & \pm 4 & \pm 4 & \pm 4 \\
\hline
\end{tabular}

Source: authors.

Table 4. Some illustrative impact scores with the resulting IPIs and CPI.

\begin{tabular}{lcc}
\hline $\begin{array}{l}\text { Parameters } \\
\text { performance }\end{array}$ & $\begin{array}{c}\text { Indicators } \\
\text { performance }\end{array}$ & $\begin{array}{c}\text { Criterion } \\
\text { performance }\end{array}$ \\
\hline $\mathrm{ImpS}_{111}=0$ & $\mathrm{IPI}_{11}=0$ & \\
$\mathrm{ImpS}_{112}=0$ & & \\
\hline $\mathrm{ImpS}_{121}=0$ & & \\
$\mathrm{ImpS}_{122}=2$ & $\mathrm{IPI}_{12}=2$ & $\mathrm{CPI}_{1}=0.666$ \\
$\mathrm{ImpS}_{123}=3$ & & \\
$\mathrm{ImpS}_{124}=3$ & & \\
\hline $\mathrm{ImpS}_{131}=1$ & $\mathrm{IPI}_{13}=0$ & \\
$\mathrm{ImpS}_{132}=-1$ & & \\
\hline
\end{tabular}

Source: authors.

\subsubsection{Estimation of performance at criteria level: aggregation of the indicators}

After the IPIs are estimated, they are aggregated to form the criterion performance index (CPI). The scheme for calculating CPIs is similar to that mentioned above for evaluating the IPIs. Similarly, the aggregation is based on equally weighted values. Theoretically, indicators should have the same importance; even when there is total compensation, aggregation occurs within a specific dimension. Nonetheless, while assessing the options within this framework, users could attribute different weights to the indicators when calculating the CPI, as outlined in Eq. (5) (where $k_{j}$ indicates the weight of the indicator $j$ ).

$\mathrm{CPI}=\frac{\sum k_{j} * \mathrm{IPI}_{j}}{\sum k_{j}}$

The results from aggregating the IPIs might reveal the sustainability performance for all five specific sustainability criteria, thus enabling comparisons between the different measures within each criterion. The most sustainable option for the desired goals must then be selected. Therefore, the fulfilment of the sustainability goals should be interpreted. Table 4 presents some impact scores with the resulting IPIs, and CPI of the sample alternative.

\subsubsection{Comparative assessment of alternative options}

To capture the interactions between the contributions of the criteria toward sustainability, the results are graphically displayed. Graphical representations are a useful starting point (Gomiero and Giampietro, 2005) during the comparative assessment because they provide a global performance overview for the alternative strategies in the context of the sustainability goals through the sustainable profiles. This general overview clearly displays the performance of the options at the level of each criterion.

In the proposed framework, the five CPIs were plotted onto a five-axis spider-gram illustrating the trade-offs. These indexes are mapped over axes, beginning at the interior and moving outward (the external limit denotes increasing level of sustainability). They are drawn relative to the adopted reference situation (target, thresholds or baseline strategy): the 0 level of the scale corresponds to the minimum sustainability level according to the reference and represents the component points of the reference graph.

Negative impacts are located inside the referential situation graph while positive ones are on the external side. Therefore, identifying which criteria perform better/worse or fall short/exceed the target/threshold is easy. A bigger diagram indicates that an option is more sustainable. Moreover, this type of graphical representation facilitates comparisons between two or more options, matching the basic goal of this paper, which is to propose a tool to assess and compare one or more option.

After the sustainability profile for the options is visualised, the decision rules must be assigned to guide the selection of the most sustainable options and propose understandable and transparent justifications for these decisions. The CPIs will rank the options according to the different decision rules; these rules reflect the diverse visions of sustainable development. The alternative options during ranking may vary depending on the compromises made between the different aspects of sustainability. To handle the tradeoffs between the sustainability criteria, some rules have been proposed for decision-making regarding sustainability assessment (Gibson et al., 2005). No specific decision rules (MCDA methods) have been established within this assessment framework. This feature is studied in the case study 
to demonstrate the potential variability in the option rankings in accordance with the adopted decision rules, possibly producing options that are ranked differently between rules. The decision-makers using this framework must choose the appropriate rule or combination of rules from the following possibilities.

\section{Rule 1: maximum net gains (optimisation logic)}

This rule delivers the most sustainable option based on the levels of cumulative contribution from each criterion toward global sustainability, selecting the option that offers the most positive net effects. Maximum net gains leads to an overall score for sustainability that incorporates all criteria in order to be able to rank alternatives and select the optimal one. The performance of the options toward sustainability might be estimated as follows:

a. Calculating a composite index of sustainability

The CPIs are collapsed into a composite index. To remain consistent with the indicators and the criteria performance calculation scheme, the Sustainability Performance Index (SPI) is a weighted average obtained using the following Eq. (6):

$$
\mathrm{SPI}=\frac{\sum w_{n} * \mathrm{CPI}_{n}}{\sum w_{n}}
$$

where $w_{n}=$ weight of criterion $n$ and $\mathrm{CPI}_{n}=$ performance of criterion $n$

To remain consistent with sustainability principles, equal importance would be ideally assigned to the CPIs during the sustainability performance assessment. However, because this framework aims to be generic, decision-makers could apply different weights, depending on their territorial specificities and sustainable development priorities. If the sample alternative obtained the following values: $\mathrm{CPI}_{1}=0.67, \mathrm{CPI}_{2}=0.6$, $\mathrm{CPI}_{3}=0.05, \mathrm{CPI}_{4}=0.16$, and $\mathrm{CPI}_{5}=1.88$, its global sustainability shown by SPI will equal to 0.67 .

In this type of composite index, a criterion could compensate for the lower performance of another criterion. Theoretically, when the five dimensions are equal, they cannot be substituted for one another. Further, the required similarities in the performance of all five sustainability dimensions seem too optimistic. Imagining a natural risk management decision that can simultaneously minimise all negative effects is difficult. Therefore, each criterion should be required to deliver net gains that positively contribute to the risk management sustainability. b. Computing the sustainability profile area

The options could be ranked according to the size of their sustainability profile. The sustainability profile ratio (SPR) could be calculated by dividing the sustainability coverage area of the option by that of the reference situation, as defined by Eq. (7), for a nine-point scale.

$$
\mathrm{SPR}=\frac{1}{80} *(a * b+b * c+c * d+d * e+e * a)
$$

where $a, b, c, d$ and $e$ are the lengths of the axes relative to the performance of each criterion.

With a nine-point scale, CPIs range from -4 to +4 . Thus, the calculations proceeded by considering the five triangles defined by the axes of the diagram and adding +4 to the value of each CPI so that the length of each arm of the star described by the criteria can be measured from the centre of the diagram where the indexes value is equal to -4 . Consequently, for the reference situation, the value of the five lengths equals 4 . The central angle of each of the five triangles is one-fifth of 360 degrees $\left(72^{\circ}\right)$ and the formula used to estimate the sustainability area (SA) of a diagram is as follows:

$\mathrm{SA}=\frac{1}{2} *(a * b+b * c+c * d+d * e+e * a) * \operatorname{Sin}\left(72^{\circ}\right)$

Using the equation 8 , the $\mathrm{SA}$ of the reference situation equals to $40 * \operatorname{Sin}\left(72^{\circ}\right)$ and equation 6 is obtained by dividing the sustainability area of the option by that of the reference situation. For the sample alternative, $\mathrm{SA}=52.7$ and $\mathrm{SPR}=1.38$ as $\mathrm{SA}$ (reference situation $)=38.04$.

Hereby, two ways of maximum net gains measurement have been proposed to give the opportunity to a decision-maker to choose depending on the manner one wishes to present the results. As a composite index (one of the most common approaches to assess overall sustainability), SPI allows for a quick assessment of the absolute sustainability performance of a given policy. Besides, the readability of the sustainability profile decreases with the number of considered criteria and alternatives. With the example of Fig. 3, it is impossible to precisely determine the biggest area among the four alternatives. To avoid a potential misinterpretation, SA and SPR quantify the absolute and relative (compared to reference situation) values of the sustainability profile. However, the rankings provided by the multi-criteria spider-gram cumulative surface area method might be biased by the arbitrary order of the criteria (Dias and Domingues, 2014). The major weakness of maximum net gains estimation is the compensatory logic. In the 


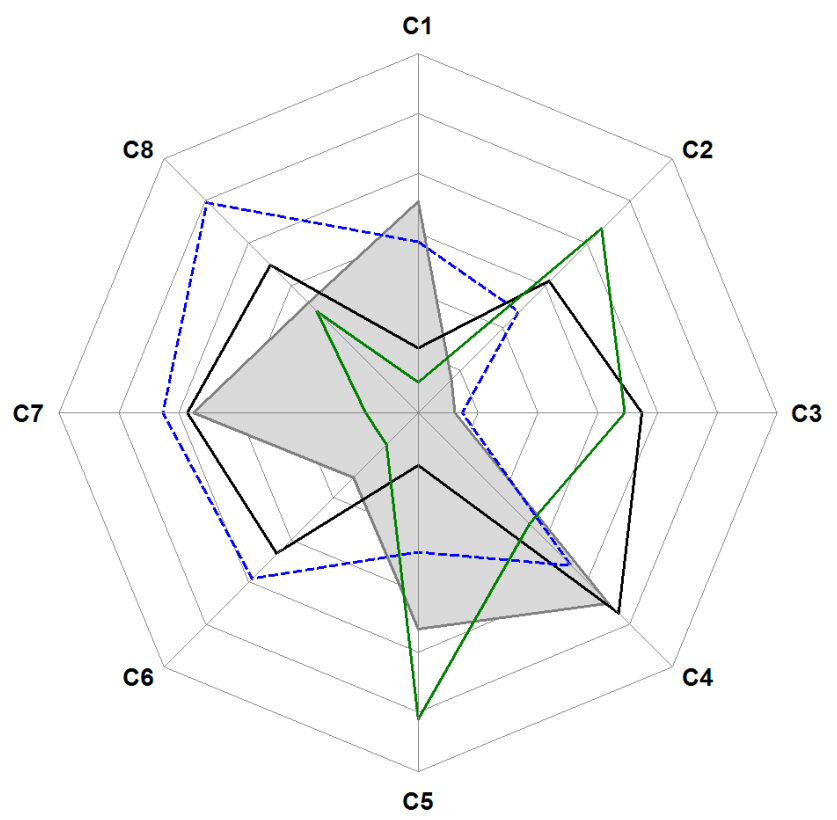

Figure 3. Spider diagram representing four alternatives and eight criteria (source: authors).

case that the decision-maker does not admit compensability, the following rules could be applied according to his specific goals.

\section{Rule 2: maximum positive performance (outranking logic)}

To avoid compensation effects among the dimensions due to aggregation, the sustainability of the options could be judged by analysing the criterion performance indexes individually. This rule focuses on positive criterion performance indexes, and the ranking could follow two distinct and complementary lines of thought. Therefore, the most sustainable option will be one of the following:

- the option with the highest number of positive performance indexes or

- the option that scores best on the most aspects of sustainability or has more of the performance indexes.

\section{Rule 3: minimum adverse performance (optimisation logic)}

The application of this rule focuses on avoiding the negative performance of the options relative to the reference. When using this rule, the ranking is based on negative indexes and the less sustainable option is the one with the lowest index.

\section{Rule 4: fixed performance range or threshold (aspiration- or goal-oriented logic)}

This rule ranks the options based on their ability to belong to a given "sustainability range" (minimum and/or maximum threshold values) for each criterion. The "sustainability range" is the largest interval in which a criterion performance index contributes to the global situation in accordance with local sustainable development. This range defines the desirable or tolerable limits of sustainability. The lower boundary is the most important because it is the minimum performance required to contribute to the sustainability. The most sustainable option is the one with the highest number of criterion performance indexes within the "sustainability ranges".

This framework is a preliminary attempt to elaborate a method for sustainability assessments regarding natural risk management decisions. The applicability of this method can be demonstrated using a case study that illustrates the use of the framework and offers improvements to it.

\section{Part 2: Application to flood management decision-making}

The methodology discussed in Part 1 was elaborated using a fictional case study inspired by real data related to natural risk cases at municipality level. This case, based on relevant urban concerns to consider when dealing with sustainability in the risk management domain, helps testing the feasibility of the suggested methodology. It provides common guidelines for the management of any type of natural risk. This part studies the applicability of the methodology through a practical situation focused on flood risk to better capture the real concerns associated with this type of risk.

\section{A case study from a municipality of the Meurthe-et-Moselle county (France)}

The study site is a community ${ }^{9}$ located within the floodplain of Moselle river, which flows across the Meurthe-et-Moselle county (France). With around 4,700 inhabitants, FloodedCity covers $18 \mathrm{~km}^{2}$. FloodedCity is situated along the Moselle, and has been affected by some severe floods (1947, 1983, 2006). It faces typically slow floods due to Moselle overloaded discharges into the city. The upper height of the maximal known flooding or reference flood (QRef) ${ }^{10}$ is near to $2.45 \mathrm{~m}$. FloodedCity adopted a flood risk prevention plan (plan de prévention des risques inondations) that delineates flood prone areas, and establishes specific regulatory constraints for existing and new buildings according to the hazard level. These constraints prohibit new constructions within

\footnotetext{
${ }^{9}$ For confidentiality reason, the name of this municipality has been disguised, and the city is referred to as FloodedCity hereafter.

${ }^{10}$ Occurred in 1947; it is approximated as a 150 -year flood.
} 
high hazard prone areas, and impose the respect of particular requirements for existing (e.g. use of cofferdam) and new (e.g. elevation above indicated threshold heights) buildings within low and moderate hazard prone areas.

\subsection{Selected alternatives}

The chosen reference situation should be the baseline policy. Therefore, four management strategies have been retained with the mayor's staff: the "do-nothing" or status quo strategy and three alternatives. Maintaining the status quo (S1) is to continue flood risk management through existing defences (with their inspection/maintenance works continued), assuming that no new measures are undertaken. After floods, assets are cleaned-up, repaired, restored, or replaced on the basis of financing from insurance schemes. The first alternative (S2) consists of willingly respecting regulatory constraints for new buildings. Any new construction situated within hazard prone area should be raised above the level of the QRef by piling foundations or crawl spaces. The second one (S3) consists of constructing a collective defence infrastructure. The main idea is to reinforce, and to raise the existing railway embankment along the Moselle so that it can be used as a dyke sufficiently high to hold back floods up to $30 \mathrm{~cm}$ higher than the QRef. The third alternative (S4) consists of willingly respecting regulatory constraints for all existing buildings situated in hazard prone areas through individual protective equipment (cofferdams, check valves, suitable seals, etc.) that prevents, limits, or delays the entrance of water into buildings.

In addition to the specific measures of flood management, each of these alternatives is associated with new development projects in flood prone areas. FloodedCity plans:

- Housing and commercial infrastructure construction, mainly in the inner of a low to moderate hazard prone area of the city with a high urban development potential. Around one hundred houses are to be constructed stepwise between 2017 and 2025, elevating them on pilings above the level of the most severe flood (QRef), and keeping in mind that any loss of flood storage due to embankment must be compensated for by the reduction in level of nearby ground (such that the same volume is available at every flood level before and after the project).

- The setting-up of economic activity plants, which will not suffer from inundations or are weakly sensitive to them (e.g. recycling of inert waste) or with security measures for their sensitive equipment (e.g. positioning equipment above the level of the QRef, use of specific materials), and which can be served by the Moselle river.

These strategies are supposed to have different characteristics while remaining identical in terms of technical complexity during implementation. The potential consequences have been reviewed to determine the most sustainable strategy. In this study, only one punctual assessment on the temporal scale was carried out. This assessment was a snapshot at a single point in time for the middle term through a 10 years prediction ${ }^{11}$. The time span chosen for the temporal scale was not entirely arbitrary. The middle term should carefully balance the short- and long-term results. The short term is too early to assess the sustainability of a risk management decision, and the long term generates more uncertainty because the future is inherently uncertain.

\subsection{Data collection}

Applying the suggested methodology to flood risk management involves using appropriate parameters sets (quantitative indicators), particularly regarding the criterion "technical and functional effectiveness". A review of literature on flood risk management helps identify relevant parameters that best fit FloodedCity local conditions, as well as flood risks descriptions. The case study was carried out using parameters like: maximum depth of the QRef, extent of the QRef, share of buildings in the flooding area with protective gear, inhabitants within the hazard prone zone, potential number of casualties for a QRef flooding, number of cultural sites within flooding limits, contaminated sites in the flooding areas, etc. These parameters are subject to change from one case study to another, as they should be tied to the particular features of the study area, the treated hazard, and the availability of the data.

Then, information related to hydrologic and hydraulic studies (flood depth and limits maps for different flooding scenarios), cartographic data on buildings (digital elevation model, housing typologies, buildings floor height relative to the natural ground level, etc.), state-damage functions, socioeconomical statistics, etc. has been collected to describe the urban area of FloodedCity, and to acquire the input data that will be used to estimate the sustainability of the three management alternatives under study. Such information has been provided by field studies, experts' surveys, geographical databases, literature, etc. Table 5 presents an extract of the worksheet. In this table, some parameters were assigned three values (low, deterministic ${ }^{12}$ and high) to capture their possible range; these values cannot be estimated as single values due to the uncertainty inherent to long-term estimations. Equal weights have been assigned to the parameters, indicators and criteria.

\footnotetext{
${ }^{11}$ This prediction should provide the following: alternative levels of vulnerability based on the future population and other factors in the territory; losses from future risks based on the current decisions (such as land-use and building codes); and impacts on and changes in the aspects of sustainability (economic vitality, ecological quality and social equity).

${ }^{12}$ Deterministic values could be average values but do not necessarily equal these values.
} 
Table 5. Extract of the "social sustainability" criterion input data from the worksheet.

\begin{tabular}{|c|c|c|c|c|c|}
\hline Indicators & Parameters & S1 & S2 & S3 & S4 \\
\hline \multirow[t]{3}{*}{$\begin{array}{l}\text { Impact on social } \\
\text { vulnerability }\end{array}$} & $\begin{array}{l}\text { Inhabitants within the hazard prone } \\
\text { area }\end{array}$ & {$[253 ; 460](380)$} & {$[447 ; 654](573)$} & $0(0)$ & {$[447 ; 654](573)$} \\
\hline & $\begin{array}{l}\text { Potential number of casualties for a } \\
\text { QRef }\end{array}$ & {$[1 ; 7](2)$} & {$[1 ; 7](2)$} & $0(0)$ & {$[1 ; 7](2)$} \\
\hline & $\begin{array}{l}\text { Social infrastructure within the hazard } \\
\text { prone area (in this case it is a railway } \\
\text { station) }\end{array}$ & $1(1)$ & $1(1)$ & $0(0)$ & $1(1)$ \\
\hline $\begin{array}{l}\text { Social } \\
\text { acceptability }\end{array}$ & - & {$[-2.5 ;-0.5](-1.5)$} & {$[2 ; 2.5](2.25)$} & {$[2.5 ; 3](2.75)$} & {$[1 ; 2](1.5)$} \\
\hline $\begin{array}{l}\text { Equity/social } \\
\text { cohesion }\end{array}$ & - & {$[-2.5 ; 0](-1.25)$} & {$[2.5 ; 5](3.75)$} & {$[1.5 ; 2](1.75)$} & {$[1 ; 2.5](1.75)$} \\
\hline Quality of life & - & {$[2 ; 2.5](2.25)$} & {$[0 ; 2.5](1.25)$} & {$[2 ; 2.5](2.25)$} & {$[-4 ; 0](-2)$} \\
\hline \multirow{2}{*}{$\begin{array}{l}\text { Territorial } \\
\text { identity }\end{array}$} & Number of cultural sites of the city & $31(31)$ & $30(30)$ & $30(30)$ & $30(30)$ \\
\hline & $\begin{array}{l}\text { Number of cultural sites within the } \\
\text { potentially exposed areas }\end{array}$ & $10(10)$ & $9(9)$ & $0(0)$ & $9(9)$ \\
\hline
\end{tabular}

Data within the square brackets indicate the range of possible values of parameters or indicators. Deterministic values are in brackets. Source: authors.

\section{Results and discussion}

This section presents and discusses the results of this case study, provided that its underlying assumptions are proven.

\subsection{Variability of the results}

This case study exhibits an important source of variability: the input data uncertainty. Sustainability assessments require precise data, but no long-term predictions are without uncertainty. These predictions could gain uncertainty from various sources (e.g. assumptions, data, methods, models) that affect the decision-making process. The content in Table 5 demonstrates the potential incidence of uncertainty. The results of the calculation for "social sustainability" CPI using the lower, deterministic and upper values from the ranges of the parameters within this table are presented in Table 6 . These results show how the ranking of alternatives could vary according to the input data. The potential range of the CPI of alternative $\mathrm{S} 2$ crosses that of alternative $\mathrm{S} 4$. These results suggest that alternatives S2 and S4 might score equally (between -0.03 and 1.17). An uncertainty analysis is necessary to improve the sustainability assessment. However, the core purpose of this paper is not to address uncertainty; further work will be conducted to address this issue. Therefore, the case study was carried out using only one set of data that was assumed to contain the deterministic values for the parameters.
Table 6. Estimated ranges of "social sustainability" performance using a twenty-one-point scale.

\begin{tabular}{lrrr}
\hline Calculation with: & S2 & S3 & S4 \\
\hline Lower values & -0.03 & 3.7 & -1.33 \\
Deterministic values & 1.15 & 4.35 & -0.05 \\
Higher values & 2.27 & 5 & 1.17 \\
\hline
\end{tabular}

Source: authors.

\subsection{Options ranking}

The results from this study are the scored criteria assigned to each alternative. Table 7 presents the obtained CPIs, the ranking of each strategy against each criterion, and the sustainability profiles (on the basis of a twenty-one-point scale). No alternative has technical, and institutional unsustainability. Regarding those criteria, the results show an overall improvement in the performance compared to the reference. Regarding "Economic sustainability" and "Environmental sustainability", alternatives S2 and S4 are predicted not to be gainful, and environmentally friendly. Figure 4 visually compares the performance of the assessed alternatives. For the integrated decision-making perspective, rankings that depend on the different decision rules are summarised in Table 8 . These results illustrate that the most sustainable solution is most likely alternative $\mathrm{S} 3$, and that the least sustainable option is alternative S2. Based on the six rules, alternative S3 ranks first six times, while alternative $\mathrm{S} 2$ ranks second twice and third three times. By ranking second three times and third 


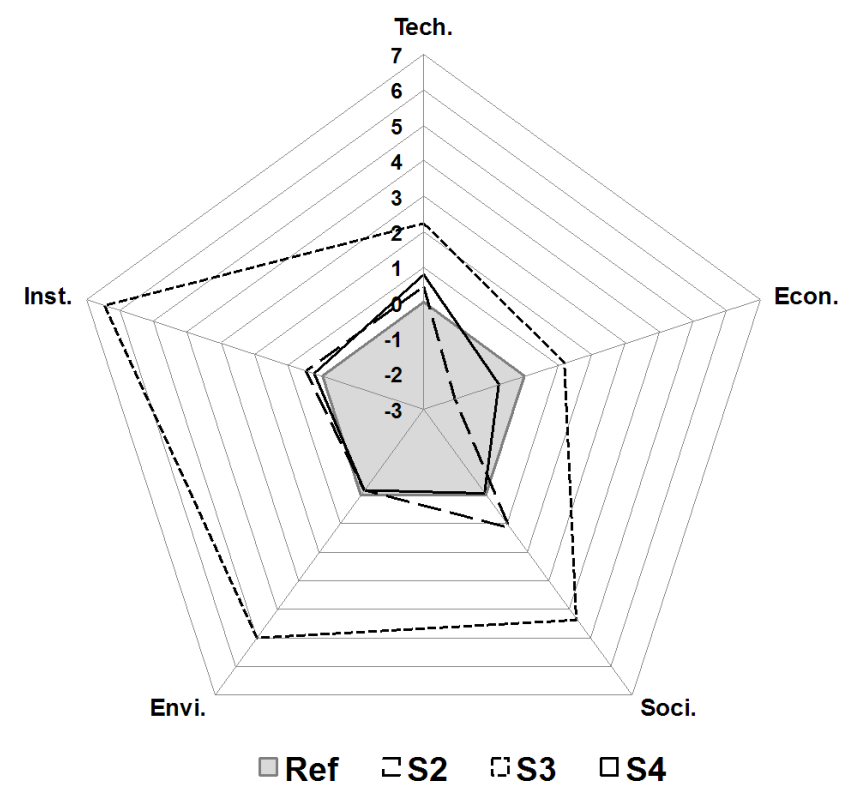

Figure 4. Graphical comparison of the sustainability profiles (source: authors).

two times, alternative $\mathrm{S} 4$ seems to be less interesting than alternative S3 but more attractive than alternative S2.

Some subjective methodological choices have been made in this basic assessment process: the use of a twenty-onepoint scale, an equal weighting of criteria, and the estimation of the final sustainability performance taking into consideration all the five selected criteria. This ranking may differ if these choices change. Therefore, a sensitivity analysis of the ranking is performed in order to identify influential choices in this case study, and to provide the decision-maker with further insight.

\subsection{Sensitivity analysis}

Sensitivity analysis seems fundamental to check if the outcomes of the adopted basic assessment process are robust, or are affected by changes in the length of the rating scale, the weighting factors of criteria, and the number of criteria retained for the sustainability performance index (SPI) calculation.

\subsubsection{Influence of the length of the rating scale}

Rankings based on a nine-point scale are summarised in Table 9. Once again, the most sustainable solution is the alternative S3 and the least sustainable option seems to be alternative S2. The contents of Tables 8 and 9 show a significant shift in rankings regarding "Highest number of positive performance indexes" and "Fixed performance threshold (e.g. CPIs $\geq 1$ )" decision rules. A pairwise comparison of alternatives $\mathrm{S} 2$ and S4 demonstrates a difference between results from the two scales. Even both rank second while using a nine-point scale, alternative $\mathrm{S} 4$ becomes third with a twentyone-point scale. Varying the length of the rating scale appears important in this case study.

\subsubsection{Influence of the weighting}

Then, it was tested whether the ranking based on the calculation of a SPI would be different from that obtained in the basic process when the weight of one separate criterion is increased, while the weights of all the other criteria remain equals. Each criterion is thus given two levels of importance relatively to the others: (1) moderate importance (the dominant criterion weight is 0.4 vs. 0.15 for the others), and (2) high importance (dominant weighting factor is 0.6 vs. 0.1 for the others). These weighting factors were chosen arbitrarily, as the idea is just to examine the effects of the importance of each sustainability aspect on ranking results in this case study. The results (Table 10) reveal that the alternative $\mathrm{S} 3$ is the most sustainable amongst all regardless of weightings. Alternative S4 ranks second when technical, economic, and environmental aspects are dominant (both moderate and high importance), while alternative S2 ranks second when social, and institutional aspects are assigned most importance (whatever the level of importance). Rankings from giving importance to social, and institutional concerns are different from the basic ranking; thus results could be sensitive to the weighting. Every case has its particular context; depending on the specific conditions of a territory, the relative importance of each criterion will differ. Consequently, decision-makers can appropriately define their own set of weights when assessing the sustainability of risk management decisions. However, they should make a comparison between results from an equal weighting approach (that is assumed to be the ideal weighting to fulfil the need to make a balanced decision), and those from the specific weighting before making decisions.

\subsubsection{Influence of excluding the "Technical and functional effectiveness" criterion}

Finally, the influence of excluding a single criterion from the SPI calculation was tested. Impacts of management decisions, regarding other criteria, are supposed to be closely tied to the "Technical and functional effectiveness" criterion. Subsequently, SPIs have been calculated taking into account only four criteria over five, using scores provided by a twenty-one-point scale, and maintaining equal weights for each of them. The obtained result is different from the basic one. The ranking from the most to least sustainable alternative is $\mathrm{S} 3(\mathrm{SPI}=4.24), \mathrm{S} 2(\mathrm{SPI}=-0.16)$, and S4 (SPI $=-0.19$ ). Results could be sensitive to excluding "Technical and functional effectiveness" criterion or not from the calculation of SPIs. Its contribution to sustainability potential seems important. This criterion reflects the core purpose of natural risk management and has a strong 


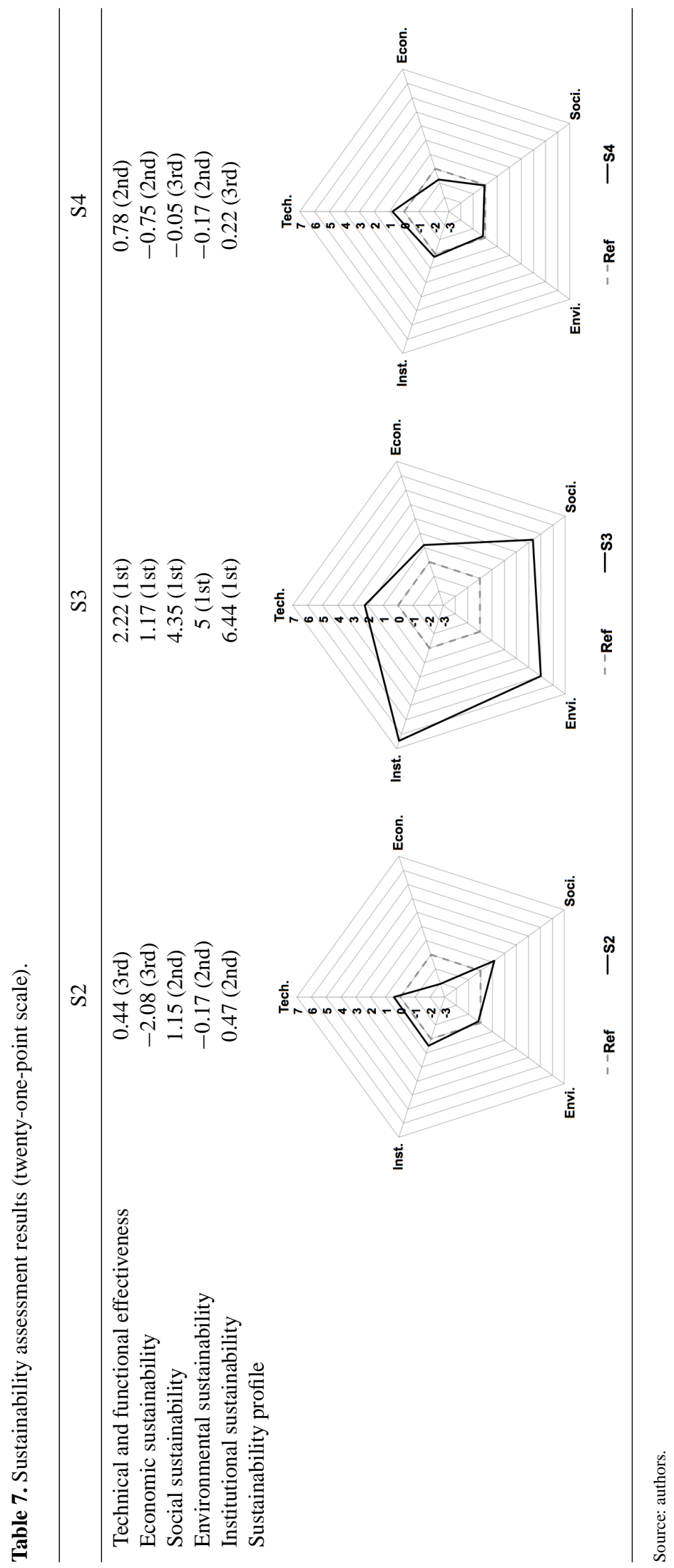


Table 8. Options ranking based on the decision rules (using a twenty-one-point scale).

\begin{tabular}{|c|c|c|c|}
\hline & $1 \mathrm{st}$ & 2nd & 3rd \\
\hline Sustainability performance index (SPI) & $\mathrm{S} 3(\mathrm{SPI}=3.84)$ & $\mathrm{S} 4(\mathrm{SPI}=0.01)$ & $\mathrm{S} 2(\mathrm{SPI}=-0.04)$ \\
\hline Sustainability profile ratio (SPR) & $\mathrm{S} 3(\mathrm{SPR}=1.92 *)$ & $\mathrm{S} 4(\mathrm{SPR}=1 *)$ & $\mathrm{S} 2(\mathrm{SPR}=0.99 *)$ \\
\hline Highest number of positive performance indexes & $\mathrm{S} 3(5$ indexes $>0)$ & S2 (3 indexes $>0)$ & $\mathrm{S} 4(2$ indexes $>0)$ \\
\hline Highest number of best performance indexes & S3 ( 5 best indexes) & S2-S4 (0 best index) & - \\
\hline Minimum adverse performance & S3 (0 negative index) & $\mathrm{S} 4\left(\mathrm{CPI}_{\mathrm{Eco}}=-0.75\right)$ & $\mathrm{S} 2\left(\mathrm{CPI}_{\mathrm{Eco}}=-2.08\right)$ \\
\hline $\begin{array}{l}\text { Fixed performance threshold. For example: } \\
\text { criteria performance indexes } \geq 1\end{array}$ & $\mathrm{~S} 3(5$ indexes $\geq 1)$ & S2 $(1$ index $\geq 1)$ & $\mathrm{S} 4(0$ index $\geq 1)$ \\
\hline
\end{tabular}

* Values obtained by preserving the order of the criteria on the graph for all of the options. Source: authors.

Table 9. Options ranking based on the decision rules (using a nine-point scale).

\begin{tabular}{|c|c|c|c|}
\hline & $1 \mathrm{st}$ & 2nd & $3 \mathrm{rd}$ \\
\hline Sustainability performance index (SPI) & $\mathrm{S} 3(\mathrm{SPI}=1.57)$ & $\mathrm{S} 4(\mathrm{SPI}=0.05)$ & $\mathrm{S} 2(\mathrm{SPI}=-0.01)$ \\
\hline Sustainability profile ratio (SPR) & $\mathrm{S} 3\left(\mathrm{SPR}=1.95^{*}\right)$ & $\mathrm{S} 4(\mathrm{SPR}=1.02 *)$ & $\mathrm{S} 2(\mathrm{SPR}=0.99 *)$ \\
\hline Highest number of positive performance indexes & $\mathrm{S} 3(5$ indexes $>0)$ & $\mathrm{S} 2-\mathrm{S} 4(3$ indexes $>0)$ & - \\
\hline Highest number of best performance indexes & S3 (5 best indexes) & S2-S4 (0 best index $)$ & - \\
\hline Minimum adverse performance & S3 (0 negative index) & $\mathrm{S} 4\left(\mathrm{CPI}_{\mathrm{Env}}=-0.17\right)$ & $\mathrm{S} 2\left(\mathrm{CPI}_{\mathrm{Eco}}=-0.67\right)$ \\
\hline $\begin{array}{l}\text { Fixed performance threshold. For example: } \\
\text { criteria performance indexes } \geq 1\end{array}$ & $\mathrm{~S} 3$ (3 indexes $\geq 1)$ & $\mathrm{S} 2-\mathrm{S} 4(0$ index $\geq 1)$ & 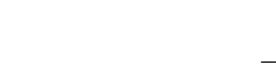 \\
\hline
\end{tabular}

* Values obtained by preserving the order of the criteria on the graph for all of the options. Source: authors.

inspirational value. Therefore, it would be more advantageous to keep it in the comparative analysis.

\subsection{Case study discussion}

The case study accounts for some features that are not often considered during the existing natural risk management processes. The findings reveal that the developed framework can provide an excellent informational resource about indicators and criteria that is optimised for each possible management strategy. The results can also highlight the shortfalls in each case. Therefore, based on this supportive analysis tool, decision-makers could compare the sustainability performance of the identified strategies and choose the most sustainable one. They could also monitor the progress toward sustainability or their failure to meet sustainability goals.

As recognised by Helming et al. (2011), "it is fair to say that no methodological framework for ex ante impact assessment will ever manage to comprehensively capture the complex relationships between changes in policy [...] and the resulting changes in social, economic, and environmental systems". No tool will ever be able to capture and reflect every possible impact of a decision. Therefore, this tool does not provide a "set of best parameters, indicators and criteria"; it instead provides a formal and credible set that might be used to support decision-making processes. This paper introduces a methodology prototype that proposes simple calculations through an accessible conceptual approach. These calcula- tions should be appropriate for managing natural risks, and are transferable to any other country.

Decision making for a sustainable risk management policy depends on the distinctive characteristics of each case study. Because the decision-makers weight the parameters, indicators and criteria, the results cannot remain the same when the aggregation framework changes. For a given territory with the same data, sustainability appraisals are liable to evolve because the weights are assigned based on value judgements. In the future and to enhance the robustness of the tool, the variance introduced by the weighting changes regarding the sustainability performance should be subjected to a sensitivity analysis.

Although uncertainty is not the focus of this paper, it is interesting to analyse the impact of the estimated performance range on sustainability profile. Figure 5 presents the shape of the possible values of CPIs of alternative S4. The space for the predicted values is situated between the first and the third graphs along the axes, demonstrating that decisions can vary between these two endpoints and can potentially include the value ranges of other options. Therefore, wider index ranges generate more uncertainty.

Ex ante sustainability assessments, as well as territorial dynamics and various forecasts, contain several assumptions. Nevertheless, these assumptions are unable to reflect the long-term characteristics of hazardous events or effects of the planned decisions because, as noted by Zhu et al. (2011), "the future is inherently uncertain, all exercises about the future are facing and should cope with great uncertainty". 
Table 10. Options ranking based on SPIs calculated with various weighting factors (using a twenty-one-point scale).

\begin{tabular}{|c|c|c|c|c|c|}
\hline & & & $1 \mathrm{st}$ & 2 nd & $3 \mathrm{rd}$ \\
\hline \multicolumn{3}{|c|}{ Equal weighting } & $\mathrm{S} 3(\mathrm{SPI}=1.57)$ & $\mathrm{S} 4(\mathrm{SPI}=0.05)$ & $\mathrm{S} 2(\mathrm{SPI}=-0.01)$ \\
\hline \multirow{10}{*}{ 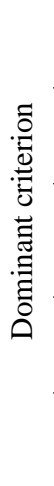 } & Technical effectiveness & Moderate importance & $\mathrm{S} 3(\mathrm{SPI}=3.43)$ & $\mathrm{S} 4(\mathrm{SPI}=0.2)$ & $\mathrm{S} 2(\mathrm{SPI}=0.08)$ \\
\hline & & High importance & $\mathrm{S} 3(\mathrm{SPI}=3.03)$ & $\mathrm{S} 4(\mathrm{SPI}=0.39)$ & $\mathrm{S} 2(\mathrm{SPI}=0.2)$ \\
\hline & Economic sustainability & Moderate importance & $\mathrm{S} 3(\mathrm{SPI}=3.17)$ & $\mathrm{S} 4(\mathrm{SPI}=-0.18)$ & $\mathrm{S} 2(\mathrm{SPI}=-0.55)$ \\
\hline & & High importance & $\mathrm{S} 3(\mathrm{SPI}=2.50)$ & $\mathrm{S} 4(\mathrm{SPI}=-0.37)$ & $\mathrm{S} 2(\mathrm{SPI}=-1.06)$ \\
\hline & Social sustainability & Moderate importance & $\mathrm{S} 3(\mathrm{SPI}=3.96)$ & $\mathrm{S} 2(\mathrm{SPI}=0.26)$ & $\mathrm{S} 4(\mathrm{SPI}=-0.01)$ \\
\hline & & High importance & $\mathrm{S} 3(\mathrm{SPI}=4.09)$ & $\mathrm{S} 2(\mathrm{SPI}=0.56)$ & $\mathrm{S} 4(\mathrm{SPI}=-0.02)$ \\
\hline & Environmental sustainability & Moderate importance & $\mathrm{S} 3(\mathrm{SPI}=4.13)$ & S4 (SPI = -0.04) & $\mathrm{S} 2(\mathrm{SPI}=-0.07)$ \\
\hline & & High importance & $\mathrm{S} 3(\mathrm{SPI}=4.42)$ & $\mathrm{S} 4(\mathrm{SPI}=-0.08)$ & $\mathrm{S} 2(\mathrm{SPI}=-0.1)$ \\
\hline & Institutional sustainability & Moderate importance & $\mathrm{S} 3(\mathrm{SPI}=4.49)$ & $\mathrm{S} 2(\mathrm{SPI}=0.09)$ & $\mathrm{S} 4(\mathrm{SPI}=0.06)$ \\
\hline & & High importance & $\mathrm{S} 3(\mathrm{SPI}=5.14)$ & $\mathrm{S} 2(\mathrm{SPI}=0.22)$ & $\mathrm{S} 4(\mathrm{SPI}=0.11)$ \\
\hline
\end{tabular}

Source: authors.

As a strategic appraisal, the sustainability assessment needs to address the inevitable uncertainties introduced during the formulation and implementation processes for the decisions: uncertainty analysis should be an integral phase of the sustainability assessment. In the specific context of risk management, this perspective is confirmed by Olbrich et al. (2009), who argue that "any meaningful assessment of sustainability of risk management strategies faces issues on a fundamental level: the necessity to address uncertainty about the system dynamics in the criterion used for the assessment". Therefore, developing methodological approaches that can handle uncertainty and examine its effects on the results of a study is critical. Further INCERDD project work is being conducted to develop a framework that accounts for uncertainty within a risk management policy-making process that is geared toward sustainable decisions.

\section{Conclusions}

Accounting for sustainability issues is currently a fundamental aspect of any decision when identifying the objectives and indicators that are used to monitor the effects of that decision. During the risk management decision process, when sustainability requirements are included, the chosen strategies would be technically, economically and environmentally efficient while enhancing the societal and institutional benefits.

This paper defined a comprehensive and structured methodology for sustainability assessments regarding natural risk management options in urban areas. It has provided an indicator-based tool that includes the technical/operational, and economic considerations, and the social, environmental, and institutional effects of risk management activities. The technical performance and institutional dimensions have

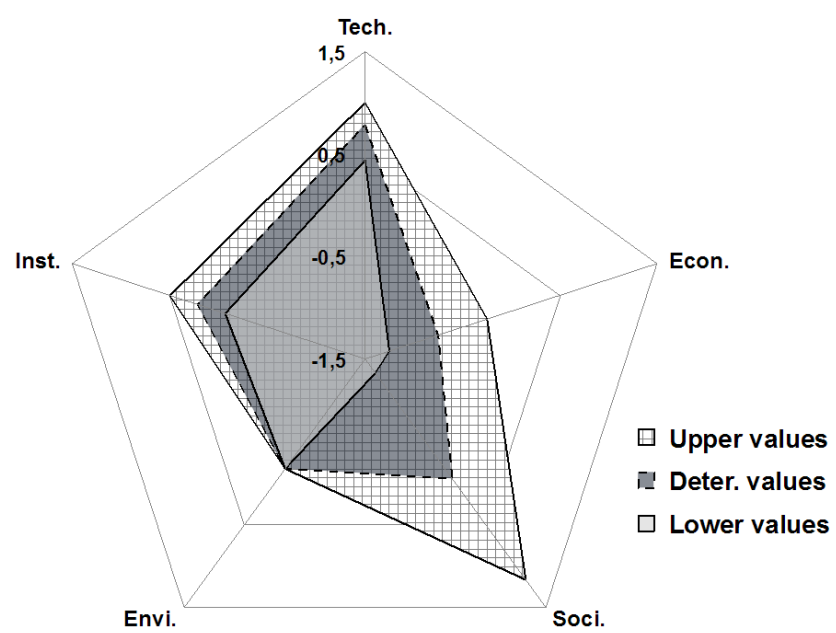

Figure 5. Sustainability profile of S4 under uncertainty (source: authors).

been added to the three common pillars of sustainable development in order to appreciate the holistic nature of sustainable natural risk management in urban areas.

By providing information regarding the sustainability performance of urban natural risk management activities, this framework should respond more objectively to the following questions: "Is sustainable risk management in a given municipality achievable?" and "What is the best way to attain this achievement?" This capability has been tested using an imaginary case study, providing results that must be validated.

This methodological framework should contribute to the sustainability of natural risk management decisions. However, the approach has only been tested using a theoretical case with virtual data, leaving it far from being a fully operational and consensual tool. This method does take a step 
forward in the field of natural and anthropogenic risk management by structuring the process that leads to decisions regarding the sustainability assessments. Although this tool is tailored to the specific field requirements of risk management, it has potential applicability to any type of decision after some revisions, particularly those that involve the indicators of the "Technical and functional effectiveness" criterion, before being used in different fields. This decision support tool could promote a systematic and coherent sustainability assessment for decisions throughout their entire life cycle.

Even the framework is proposed to assess the sustainability of future decisions; it could also be a retrofit guide for sustainable update or adaptation of existing decisions. It could help first indicate their strength, weakness, and failures. Then, sustainability merits of predetermined retrofit alternatives could be assessed with a view to select the most beneficial ones. Retrofitting sustainability into previous decisions could, at one hand, help correct their weaknesses by integrating aspects formerly ignored, and at the other, be a strategic way to enhance sustainable risk management as it could help gain time, resources, etc.

Acknowledgements. The authors would like to acknowledge the National Research Agency (Agence Nationale de la Recherche ANR) for funding the research (INCERDD project) leading to this paper.

Edited by: P. Bubeck

Reviewed by: A. Donnelly, A. I. B. Idrissa Bokoye, and one anonymous referee

\section{References}

Achet, S. H. and Fleming, B.: A watershed management framework for mountain areas: Lessons from 25 years watershed conservation in Nepal, J. Environ. Plann. Manage., 49, 675-694, 2006.

Acosta-Alba, I. and van der Werf, H. M. G.: The use of reference values in indicator-based methods for the environmental assessment of agricultural systems, Sustainability, 3, 424-442, 2011.

Agrawala, S. (Ed.): Climate change in the European Alps: Adapting winter tourism and natural hazards management, Organization for Economic Co-operation and Development (OECD) Publishing, Paris, France, 127 pp., 2007.

Bragança, L., Mateus, R., and Koukkari, H.: Perspectives of building sustainability assessment, in: Portugal SB07 - Sustainable construction, materials and practices, edited by: Bragança, L., Pinheiro, M., Jalali, S., Mateus, R., Amoêda, R., and Guedes, M. C., Challenge of the industry for the new millennium, IOS Press, Amsterdam, 356-365, 2007.

Bragança, L., Mateus, R., and Koukkari, H.: Building sustainability assessment, Sustainability, 2, 2010-2023, 2010,

Carreño, M. L., Cardona, O. D., and Barbat, A. H.: A disaster risk management performance index, Nat. Hazards, 41, 1-20, 2007.

Degg, M.: Natural hazards in the urban environment: the need for a more sustainable approach to mitigation, in: Geohazards in Engineering Geology, edited by: Maund, J. G. and Eddleston, M.,
Engineering Geology Special Publications, 15, Geological Society, London, 329-337, 1998.

Di Mauro, C., Bouchon, S., Carpignano, A., Golia, E., and Peressin, S.: Definition of multi-risk maps at regional level as management tool: Experience gained by civil protection authorities of Piemonte region, Proceedings of the 5th Conference on Risk Assessment and Management in the Civil and Industrial Settlements, 17-19 October 2006, Pisa, Italy, 12 pp., available at: http://conference.ing.unipi.it/vgr2006/archivio/Archivio/ 2006/Articoli/700196.pdf, 2006.

Dias, L. C. and Domingues, A. R.: On multi-criteria sustainability assessment: Spider-gram surface and dependence biases, Appl. Energy, 113, 159-163, 2014.

Dolan, J. G.: Multi-criteria clinical decision support: A primer on the use of multiple criteria decision making methods to promote evidence-based, patient-centered healthcare, Patient, 3, 229-248, 2010.

Donnelly, A., Jennings, E., Mooney, P., Finnan, J., Lynn, D., Jones, M., O’Mahony, T., Thérivel, R., and Byrne, G.: Workshop approach to developing objectives, targets and indicators for use in SEA, J. Environ. Assess. Pol. Manage., 8, 135-156, 2006.

Donnelly, A., Jones, M., O’Mahony, T., and Byrne, G.: Selecting environmental indicator for use in strategic environmental assessment, Environ. Impact Assess. Rev., 27, 161-175, 2007.

Faber, M. H.: Critical issues in the management of catastrophic and global risks, Proceedings of the International Symposium on Reliability Engineering and Risk Management, 23-26 September 2010, Shanghai, China, 13 pp., 2010.

Farley, J., Erickson, J. D., and Daly, H. E.: Ecological economics: A workbook for problem-based learning, Washington, 215 pp., 2005.

Fekete, A., Damm, M., and Birkmann, J.: Scales as a challenge for vulnerability assessment, Nat. Hazards, 55, 729-747, 2010.

Franco, L. A. and Montibeller, G.: Problem structuring for multicriteria decision analysis interventions, Working paper OR 09115, 25 pp., available at: http://www.lse.ac.uk/management/ documents/WP-09-115.pdf, 2009.

Freedman, P. L., Nemura, A. D., and Dilks, D. W.: Viewing total maximum daily loads as a process, not a singular value: Adaptive watershed management, J. Environ. Eng., 130, 695-702, 2004.

Gafsi, M. and Favreau J. L.: Indicator-based method for assessing organic farming sustainability, in: Methods and procedures for building sustainable farming systems, edited by: Marta-Costa, A. A. and Soares da Silva, E. L. D. G., Application in the European context, Springer, 175-187, 2013.

Galloway, G.: Integrated flood management case study - USA : Flood management - Mississippi river, The Associated Programme on Flood Management, Geneva, Switzerland, 12 pp., available at: http://www.apfm.info/publications/casestudies/cs_ usa_mississippi_full.pdf, 2004.

Genserik, R.: Integrating risk and sustainability: A holistic and integrated framework for optimizing the risk decision and expertise rad (ORDER), Disaster Advances, 5, 25-32, 2012.

Gibson, R. B.: Sustainability assessment: Basic components of a practical approach, Impact Assessment and Project Appraisal, 24, 170-182, 2006.

Gibson, R. B., Hassan, S., Holtz, S., Tansey, J., and Whitelaw, G.: Sustainability assessment: Criteria and processes, Earthscan Publishers, London, 254 pp., 2005. 
Glasson-Cicognani, M. and Berchtold, A.: Imputation des données manquantes: Comparaison de différentes approches, 42 Journées de Statistique, 24-28 May, Marseille, France, 6 pp., available at: http://hal.inria.fr/docs/00/49/46/98/PDF/p37.pdf, 2010.

Glavovic, B. C.: Realising the promise of natural hazards planning: An Australasian perspective, The Aust. J. Disaster Trauma Stud., 1, available at: http://www.massey.ac.nz/ trauma/issues/2010-1/ glavovic2.htm, 2010.

Global Reporting Initiative: Sustainability Reporting Guidelines (G4), Global Reporting Initiative, available at: https://www.globalreporting.org/resourcelibrary/ GRIG4-Part1-Reporting-Principles-and-Standard-Disclosures. pdf, Amsterdam, 92 pp., 2013.

Gomiero, T. and Giampietro, M.: Graphic tools for data representation in integrated analysis of farming systems, Int. J. Global Environ. Issues, 5, 264-301, 2005.

González, A., Donnelly, A., Jones, M., Chrysoulakis, N., and Lopes, M.: A decision-support system for sustainable urban metabolism in Europe, Environ. Impact Assess. Rev., 38, 109-119, 2013.

Graymore, M. L. M., Sipe, N. G., and Rickson, R. E.: Sustaining human carrying capacity: A tool for regional sustainability assessment, Ecol. Econom., 69, 459-468, 2010.

Hansson, M., Danielson, M., and Ekenberg, L.: A framework for evaluation of flood management strategies, J. Environ. Manage., 86, 465-480, 2008.

Helming, K., Diehl, K., Kuhlman, T., Jansson, T., Verburg, P. H., Bakker, M., Perez-Soba, M., Jones, L., Johannes Verkerk, P., Tabbush, P., Breton Morris, J., Drillet, Z., Farrington, J., LeMouël, P., Zagame, P., Stuczynski, T., Siebelec, G., and Wiggering, H.: Ex ante impact assessment of policies affecting land use - Part B: Application of the analytical framework, Ecol. Soc., 16, 23 pp., available at: http://www.ecologyandsociety.org/ vol16/iss 1/art29/, 2011.

Institut National de la Statistique et des Etudes Economiques (INSEE), available at: http://www.insee.fr/fr/themes/document.asp? ref_id=T11F014, last access: 9 April 2013.

Juwana, I., Muttil, N., and Perera, B. J. C.: Indicator-based water sustainability assessment - A review, Sci. Total Environ., 438, 357-371, 2012.

Kang, M. G., Jeong, H. S., Lee, J. H., and Kang, B. S.: Assessing national flood management using a sustainable flood management framework, Water Pol., 15, 418-434, 2013.

Kenyon, W.: Evaluating flood risk management options in Scotland: A participant-led multi-criteria approach, Ecol. Econom., 64, 7081, 2007.

Kienberger, S., Blaschke, T., and Zaidi, R. Z.: A framework for spatio-temporal scales and concepts from different disciplines: the "vulnerability cube", Nat. Hazards, 68, 1343-1369, 2013.

Klijn, F., de Bruijn, K., McGahey, C., Mens, M., and Wolfert, H.: Towards sustainable flood risk management: On methods for design and assessment of strategic alternatives exemplified on the Schelde Estuary. FLOODsite project report, Executive summary, 30 pp., available at: http://www.floodsite.net/html/ partner_area/project_docs/T14_08_02_sustainable_flood_risk_ management_Schelde_ExecSum_V1_2_P01.pdf, 2009.

Knott, G. and Fox, A.: A model of sustainable risk management, The magazine of the emergency planning society, 62, 38-42, 2010.
Ko, T. G.: Development of a tourism sustainability assessment procedure: A conceptual approach, Tourism Manage., 26, 431-445, 2005.

Kundzewicz, Z. W.: Non-structural flood protection and sustainability, Water Int., 27, 3-13, 2002.

Lekuthai, A. and Vongvisessomjai, S.: Intangible flood damage quantification, Water Resour. Manage., 15, 343-362, 2001.

McBean, G. and Henstra, D.: Climate change, natural hazards and cities, 16 pp., available at: http://www.iclr.org/images/Climate_ Change,_Natural_Hazards_and_Cities.pdf, 2003.

McGahey, C., Sayers, P., Mens, M., Luther, J., and Schanze, J.: An approach to planning for sustainable flood risk management in the long-term (supported by prototype tools). FLOODsite project report, Executive summary, $16 \mathrm{pp}$., available at: http://www.floodsite.net/html/partner_area/project_docs/T18_ 07_03_Task_18_Executive_Summary_V2_0_P01.pdf, 2009.

Mdaghri, Z. A.: Intégration de la pensée cycle de vie aux études d'impacts: Cas du site minier Raglan, PhD Thesis, Université de Montréal, Canada, 243 pp., 2008.

Mileti, D.: Disasters by Design: A Reassessment of Natural Hazards in the United States, Washington, D.C.: The Joseph Henry Press, 376 pp., 1999.

Ministère de l'Écologie, du Développement durable, des Transports et du Logement (MEDDTL). Service de l'économie, de l'évaluation et de l'intégration du développement durable: Fiche exemple 12: Hiérarchisation et territorialisation des enjeux, 5 pp., available at: http://www.developpement-durable.gouv.fr/ IMG/pdf/F12_MEDDTL_Fiches_Guide_Ev_Env_Doc_Urba_ BD_nov2011.pdf, 2011.

Mitchell, J. K.: Hazards in changing cities, Appl. Geogr., 18, 1-6, 1998.

Myllyviita, T., Leskinen, P., and Seppälä, J.: Impact of normalisation, elicitation technique and background information on panel weighting results in life cycle assessment, The Int. J. Life Cycle Assess., 19, 379-386, 2014

Ni, J., Sun, L., Li, T., Huang, Z., and Borthwick, A. G. L.: Assessment of flooding impacts in terms of sustainability in mainland China, J. Environ. Manage., 91, 1930-1942, 2010.

OECD/JRC: Handbook on constructing composite indicators. Methodology and user guide, OECD Publishing, Paris, France, 158 pp., available at: http://www.oecd.org/std/42495745.pdf, 2008.

Olbrich, R., Quaas, M. F., and Baumgärtner S.: Sustainable use of ecosystem services under multiple risks - A survey of commercial cattle farmers in semi-arid rangelands in Namibia, Working Paper Series in Economics, No. 137, Leuphana University of Lüneburg, Germany, 24 pp., 2009.

Peltonen, L.: Recommendations for a risk mitigation oriented European spatial Policy, in: Natural and technological hazards and risks affecting the spatial development of European regions, edited by: Schmidt-Thomé, P., Geological survey of Finland, Special paper 42, 153-167, 2006.

Poulard, C., Lafont, M., Lenar-Matyas, A., and Łapuszek, M.: Flood mitigation designs with respect to river ecosystem functions - A problem oriented conceptual framework, Ecol. Eng., 36, 69-77, 2010.

Poveda, C. A. and Lipsett, M. G.: A review of sustainability assessment and sustainability/environmental rating systems and credit weighting tools, J. Sustain. Develop., 4, 36-55, 2011. 
Putri, P. W. and Rahmanti, A. S.: Jakarta Waterscape: From structuring water to 21 st century hybrid nature?, Nakhara: J. Environ. Design Plann., available at: http://www.arch.chula.ac.th/nakhara/ files/article/i2lymtL2t4Wed85655.pdf, 59-74, 2010.

Roy, B.: Paradigms and challenges, in: Multi Criteria Decision?Analysis: State of the Art Surveys, edited by: Figueira, J., Greco, S., and Ehrgott, M., Springer, 3-24, 2005.

Saunders, W.: How long is your piece of string - Are current planning timeframes for natural hazards long enough? Paper presented at the Planning pathway to the future, 20-23 April, Christchurch, New Zealand, 6 pp., available at: http://www.planning.org.nz/Folder?Action=View\% 20File\&Folder_id=185\&File=Saunders.pdf, 2010a.

Saunders, W.: Sustainable urban design for natural hazard risk reduction. Proceedings of New Zealand Sustainable Building Conference: SB10 - Innovation and transformation, 2628 May 2010, Te Papa, Wellington, New Zealand, 11 pp., available at: http://www.branz.co.nz/cms_show_download.php? $\mathrm{id}=499 \mathrm{~b} 83 \mathrm{c} 7139 \mathrm{~b} 64 \mathrm{f} 02 \mathrm{c} 5 \mathrm{f} 62 \mathrm{~d} 3 \mathrm{ee} 76 \mathrm{cbac} 5 \mathrm{fef} 0 \mathrm{~d} 5 \mathrm{f}, 2010 \mathrm{~b}$.

Scottish Executive: Sustainable flood management sub-group report, Report for 23 September 2004 NTAG Meeting, 21 pp., available at: http://www.scotland.gov.uk/Resource/Doc/ 1223/0007095.pdf, 2004

Scottish Executive: Sustainable flood management pilot study (Final report), MWH and Jacobs Babtie, Edinburgh, UK, 57 pp., available at: http://www.scotland.gov.uk/Resource/Doc/ 1223/0020971.pdf, 2005

Singh, R. K., Murty, H. R., Gupta, S. K., and Dikshit, A. K.: An overview of sustainability assessment methodologies, Ecol. Indicators, 15, 281-299, 2012.

Tompkins, E. L. and Adger, W. N.: Does adaptive management of natural resources enhance resilience to climate change?, Ecol. Soc., 9, 10, available at: http://www.ecologyandsociety.org/vol9/ iss2/art10/, 2004.

Tugnoli, A., Landucci, G., and Cozzani, V.: Sustainability assessment of hydrogen production by steam reforming, Int. J. Hydro. Energ., 33, 4345-4357, 2008.

Turner II, B. L., Kasperson, R. E., Matson, P. A., McCarthy, J. J., Corell, R. W., Christensen, L., Eckley, N., Kasperson, J. X., Luers, A., Martello, M. L., Polsky, C., Pulsipher, A., and Schiller, A.: A framework for vulnerability analysis in sustainability science, Proc. Natl. Acad. Sci. USA, 100, 8074-8079, 2003.

Turner, R. K., Adger, W. N., Crooks, S., Lorenzoni, I., and Ledoux, L.: Sustainable coastal resources management: Principles and practice, Nat. Resour. Forum, 23, 275-286, 1999.

UNISDR: Terminology on Disaster Risk Reduction, available at: http://www.unisdr.org/we/inform/terminology, 2009.
Van Cauwenbergh, N., Biala, K., Bielders, C., Brouckaert, V., Franchois, L., Garcia Cidad, V., Hermy, M., Mathijs, E., Muys, B., Reijnders, J., Sauvenier, X., Valckx, J., Vanclooster, M., Van der Veken, B., Wauters, E., and Peeters, A.: SAFE - A hierarchical framework for assessing the sustainability of agricultural systems, Agr. Ecosyst. Environ., 120, 229-242, 2007.

Vanneuville, W., Kellens, W., De Maeyer, P., Reniers, G., and Witlox, F.: Is "flood risk management" identical to "flood disaster management"? available at: http://www.earthzine.org/2011/03/21/ is-flood-risk-management-identical-to-flood-disaster-management/, 2011.

Weiland, U., Kindler, A., Banzhaf, E., Ebert, A., and Reyes-Paecke, S.: Indicators for sustainable land use management in Santiago de Chile, Ecol. Indicators, 11, 1074-1083, 2011.

Werritty, A.: Sustainable flood management: Oxymoron or new paradigm?, Area, 38, 16-23, 2006.

Wiek, A. and Binder, C.: Solution spaces for decision-making - A sustainability assessment tool for city-regions, Environ. Impact Assess. Rev., 25, 589-608, 2005.

Wurbs, R. A.: Optimal sizing of flood damage reduction measures based on economic efficiency, Int. J. Water Resour. Develop., 12, 5-16, 1996.

Zahm, F., Viaux, P., Girardin, P., Vilain, L., and Mouchet, C.: Farm sustainability assessment using the IDEA Method: From the concept of farm sustainability to the case studies on French farms, in: From common principles to common practices. Proceedings and Outputs of the 1st Symposium of the International Forum on Assessing Sustainability in Agriculture (INFASA), edited by: Häni, F. J., Pintér, L., and Herren, H. R., International Institute of Sustainable Development and Swiss College of Agriculture, Bern, 77-110, 2006.

Zhou, P., Ang, B. W., and Poh, K. L.: Comparing aggregating methods for constructing the composite environmental index: An objective measure, Ecol. Econom., 59, 305-311, 2006.

Zhou, P., Ang, B. W., and Poh, K. L.: A mathematical programming approach to constructing composite indicators, Ecol. Econom., 62, 291-297, 2007.

Zhu, Z., Bai, H., Xu, H., and Zhu, T.: An inquiry into the potential of scenario analysis for dealing with uncertainty in strategic environmental assessment in China, Environ. Impact Assess. Rev., 31, 538-548, 2011.

Zihri, G.: Risques liés aux ouvrages souterrains: Constitution d'une échelle de dommages, PhD Thesis, Ecole des Mines de Nancy, France, 226 pp., 2004. 